NBER WORKING PAPER SERIES

\title{
SHOULD THE GOVERNMENT BE PAYING INVESTMENT FEES ON \$3 TRILLION OF TAX-DEFERRED RETIREMENT ASSETS?
}

\author{
Mattia Landoni \\ Stephen P. Zeldes \\ Working Paper 26700 \\ http://www.nber.org/papers/w26700 \\ NATIONAL BUREAU OF ECONOMIC RESEARCH \\ 1050 Massachusetts Avenue \\ Cambridge, MA 02138 \\ January 2020
}

The authors would like to acknowledge the helpful comments of Dan Bergstresser, Patrick Bolton, Emiliano Catonini, Kent Daniel, Philippe d'Astous, Michael Halling, Glenn Harrison, Daniel Hemel, Charles Jones, David Laibson, Deborah Lucas, Pierre-Carl Michaud, Brett Myers, Emi Nakamura, Thomas Philippon, Jim Poterba, Jon Steinsson, Simon Straumann; seminar participants at the Columbia Business School Finance Free Lunch, the Columbia Macro Lunch, CEIBS, Baruch College, Texas A\&M Mays Business School, the Federal Reserve Bank of Chicago, EIEF, Yonsei University, the Federal Reserve Bank of Boston, and Vanguard; and conference participants at the Red Rock Finance Conference 2016, ESSFM Gerzensee 2017, the World Finance Conference 2017, DCIIA 2017, the EUROFIDAI Paris December 2017 meeting, the European Finance Association 2018 meeting, and the 2019 MIT GCFP 6th Annual Conference. We thank Abdullah Al-Sabah, Matt Hochhauser, Rachel Williams, and Logan Young for research assistance. Stephen Zeldes is an external advisor at FeeX.com, and is grateful to Eyal Halahmi, Yoav Zurel, and the rest of the team there for their help understanding and measuring investment management fees. The views expressed herein are those of the authors and do not necessarily reflect the views of the National Bureau of Economic Research.

At least one co-author has disclosed a financial relationship of potential relevance for this research. Further information is available online at http://www.nber.org/papers/w26700.ack

NBER working papers are circulated for discussion and comment purposes. They have not been peer-reviewed or been subject to the review by the NBER Board of Directors that accompanies official NBER publications.

(C) 2020 by Mattia Landoni and Stephen P. Zeldes. All rights reserved. Short sections of text, not to exceed two paragraphs, may be quoted without explicit permission provided that full credit, including $(\odot$ notice, is given to the source. 
Should the Government be Paying Investment Fees on $\$ 3$ Trillion of Tax-Deferred Retirement Assets?

Mattia Landoni and Stephen P. Zeldes

NBER Working Paper No. 26700

January 2020

JEL No. D14,G11,G23,G28,G51,H21,J26,J32

\begin{abstract}
Under standard assumptions, both individuals and the government are indifferent between traditional tax-deferred retirement accounts and "front-loaded" (Roth) accounts. When we add investment fees to this benchmark, individuals are still indifferent but the government is not. We estimate that tax deferral increases demand for asset management services by $\$ 3$ trillion, causing the government to pay $\$ 20.7$ billion in corresponding annual fees. In a general equilibrium model with asset management services as differentiated products, we examine the incidence and welfare implications of the added demand. Tax deferral in our model produces a larger asset management industry, higher taxes, and lower social welfare.
\end{abstract}

\author{
Mattia Landoni \\ Cox School of Business \\ Southern Methodist University \\ 6212 Bishop Blvd, Fincher 337 \\ Dallas, TX 75275 \\ mattia.landoni@gmail.com \\ Stephen P. Zeldes \\ Graduate School of Business \\ Columbia University \\ 3022 Broadway, Uris 825 \\ New York, NY 10027-6902 \\ and NBER \\ stephen.zeldes@gsb.columbia.edu
}

An online appendix is available at http://www.nber.org/data-appendix/w26700 


\section{Introduction}

Retirement savings systems around the world incorporate tax incentives designed to increase saving and enhance retirement security. The traditional and most common incentive system is tax deferral: the U.S. alone has $\$ 23.5$ trillion of tax-deferred retirement assets in both employer-based accounts (including defined-benefit plans and defined-contribution plans, or "401(k)s") and individual retirement accounts ("IRAs"). A tax deferral system works by back-loading taxation, i.e., exempting contributions to retirement accounts from current income taxation and then taxing the principal and returns upon withdrawal.

Although the vast majority of retirement assets is held in Traditional (henceforth capitalized) accounts, an alternative system in which taxes are front-loaded is becoming increasingly widespread. ${ }^{1}$ Under this system, referred to as "Roth", contributions are made with after-tax income, but then principal and returns are not taxed at any future time. A benchmark result under standard assumptions, including the equality of tax rates in working and retirement years, is that each system results in the same cash flows for the individual, and the same present value of tax revenue for the government, with only the timing of taxes differing across systems.

During the formulation of the 2017 U.S. tax reform, Congress considered including provisions for "Rothification", i.e., a shift away from Traditional accounts in favor of front-loaded taxation (see, e.g., Tergesen and Rubin, 2017). Although these provisions were not included in the final tax reform law (Public Law 115-97 of 12/22/2017), the debate raised public awareness about the alternative ways of structuring retirement tax incentives. ${ }^{2}$

Much of the U.S. debate focused on the political economy aspects of the choice, i.e., whether front-loading tax revenue with a Roth system would encourage irresponsible fiscal policy. We abstract from this debate. Instead, our contribution is to highlight another important channel through

\footnotetext{
${ }^{1}$ In the U.S., Roth accounts, named after the senator who originally proposed them, became available as Roth IRAs in 1997 and Roth 401(k)s in 2001. Roth IRA contributions have been higher than Traditional ones since 1999, and Roth assets have climbed to about $9 \%$ of total IRA assets. Similar trends are occurring in Canada and the U.K., which started with tax-deferred accounts and later introduced front-loaded ones as an additional option.

${ }^{2}$ Similarly, the U.K. Treasury in 2015 launched a formal consultation on, among other things, whether front-loaded or back-loaded taxation is preferable (Osborne, 2015; Buttonwood, 2015).
} 
which the timing of taxation affects welfare outcomes: investment funds, recordkeepers, and financial advisors ("asset managers" for brevity) charge fees. By deferring tax revenue with a Traditional system, the government generates an additional $\$ 3$ trillion in assets under management (AUM) corresponding to the amount in retirement accounts that will be used to pay future taxes. Assuming that fees are a constant percentage of AUM, we estimate that these asset management services cost the government $\$ 20.7$ billion annually in fees. We argue that the extra services paid for create little value for the government and therefore we refer to the corresponding fees as an "implicit subsidy" to the financial industry. ${ }^{3}$ Further, we solve a general equilibrium model in which asset management services are represented as differentiated products and show that tax deferral produces a larger asset management industry, lower tax revenue, and lower social welfare. ${ }^{4}$

Section 2 begins with the standard benchmark equivalence result. Under a few simplifying assumptions, including the constancy of the tax rate across working and retirement years, and in the absence of fees, (i) individuals are indifferent between Traditional and Roth accounts, which yield identical cash flow streams; and (ii) the timing of government cash flows differs across accounts, but the future value (or present value) of tax revenue is the same. ${ }^{5}$ The first two panels of Figure 1, labeled Roth and Traditional, show that an individual who puts aside $\$ 100$ of pre-tax income to fund either a Roth or Traditional account (consuming the same amount in each case) ends up with the same amount of retirement consumption (\$175) under either account. At the same time, under either account, the future value of government revenue is $\$ 75$. The third panel, labeled "Traditional (As If)," provides intuition for the equivalence result by decomposing a Traditional account into a Roth-like individual account plus an implicit government account equal to the balance of deferred taxes. An individual with $\$ 100$ in a tax-deferred retirement account who faces a $30 \%$ tax rate in

\footnotetext{
${ }^{3} \mathrm{~A}$ traditionally-defined subsidy drives a wedge between the prices received by producers and those paid by consumers, whereas the "subsidy" here takes the form of artificial demand that creates a shift in the demand curve and helps producers cover their fixed costs.

${ }^{4}$ Our focus is on retirement accounts because they are the largest and cleanest instance of tax deferral, but the implications of our findings extend to other forms of income subject to tax deferral, such as capital gains and deferred compensation.

${ }^{5}$ We abstract from a variety of real-world considerations that could lead individuals to prefer one type of account over the other, including progressive taxation and differences in effective contribution limits, withdrawal penalties, and required minimum distributions. We briefly discuss some of these features in Section 2.
} 


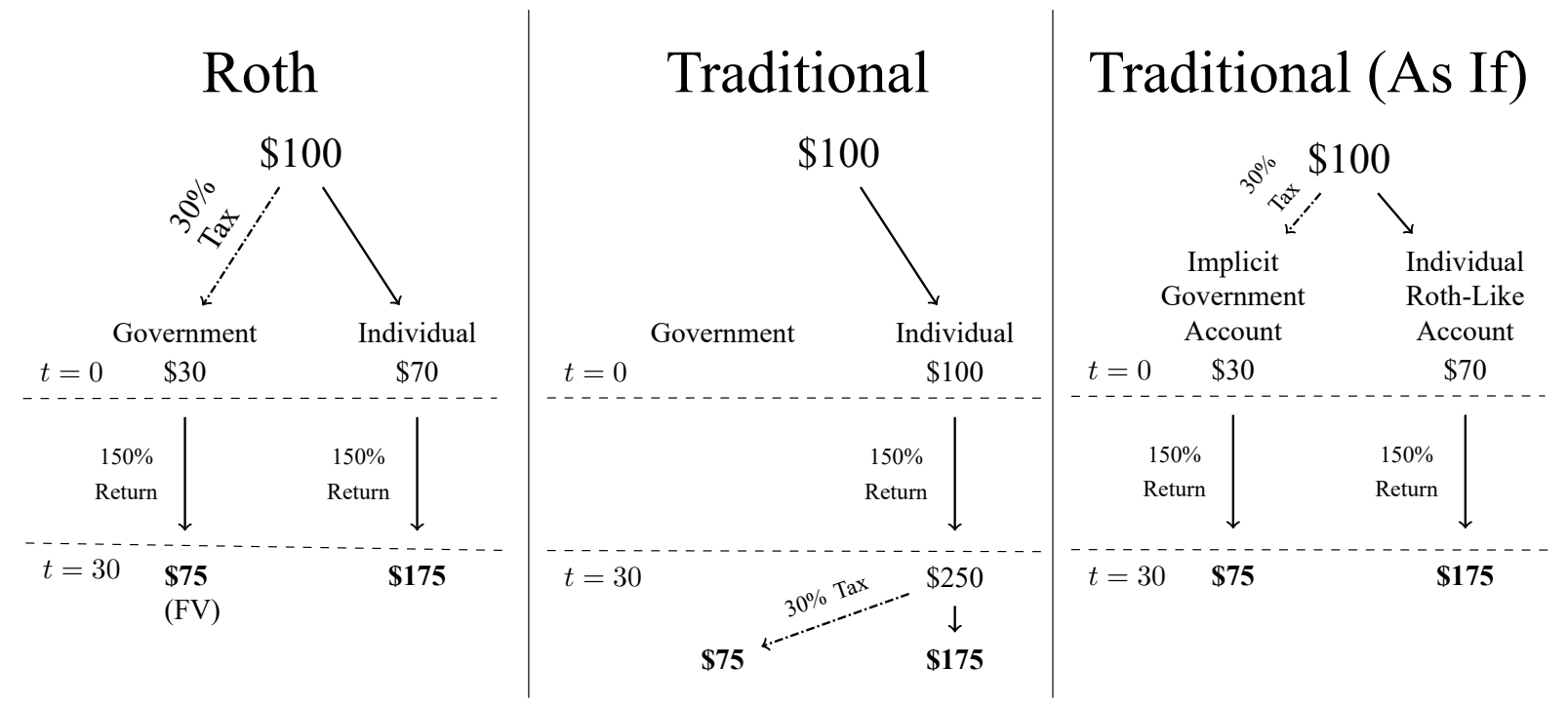

Figure 1: Benchmark equivalence result. Traditional is equivalent to a Roth account plus an implicit government account equal to the balance of deferred taxes. Without asset management fees, the two accounts yield the same cash flows for individuals, and the same future value (FV) of cash flows for the government. A $150 \%$ return is approximately equal to the total return on a 30 -year Treasury bond (3.10\% for 30 years).

retirement could be seen as owning $\$ 70$ in a Roth-like account, with the government owning the remaining $\$ 30$.

We add one additional realistic element to this benchmark model: fees paid on retirement accounts. In Figure 2, we show that the individual ends up with the same future value $(\$ 140=\$ 175$ - \$35 in fees) under each type of account, and thus remains indifferent between the two. However, because under Traditional the government levies taxes later, the account size is larger, and therefore total fees are also larger (\$50 instead of \$35) and the future value of government revenues is lower (\$60 instead of \$75). The third panel again shows the decomposition into a Roth-like account and an implicit government account. Under Traditional the government effectively pays $\$ 15$ in extra investment fees on its implicit account, something it does not incur with Roth accounts.

Expanding the model to allow for differences in tax rates during work and retirement introduces the equivalent of a "government match" (which can be positive or negative) into the Traditional program. We show that if the government adds to the Roth account an explicit government match of 


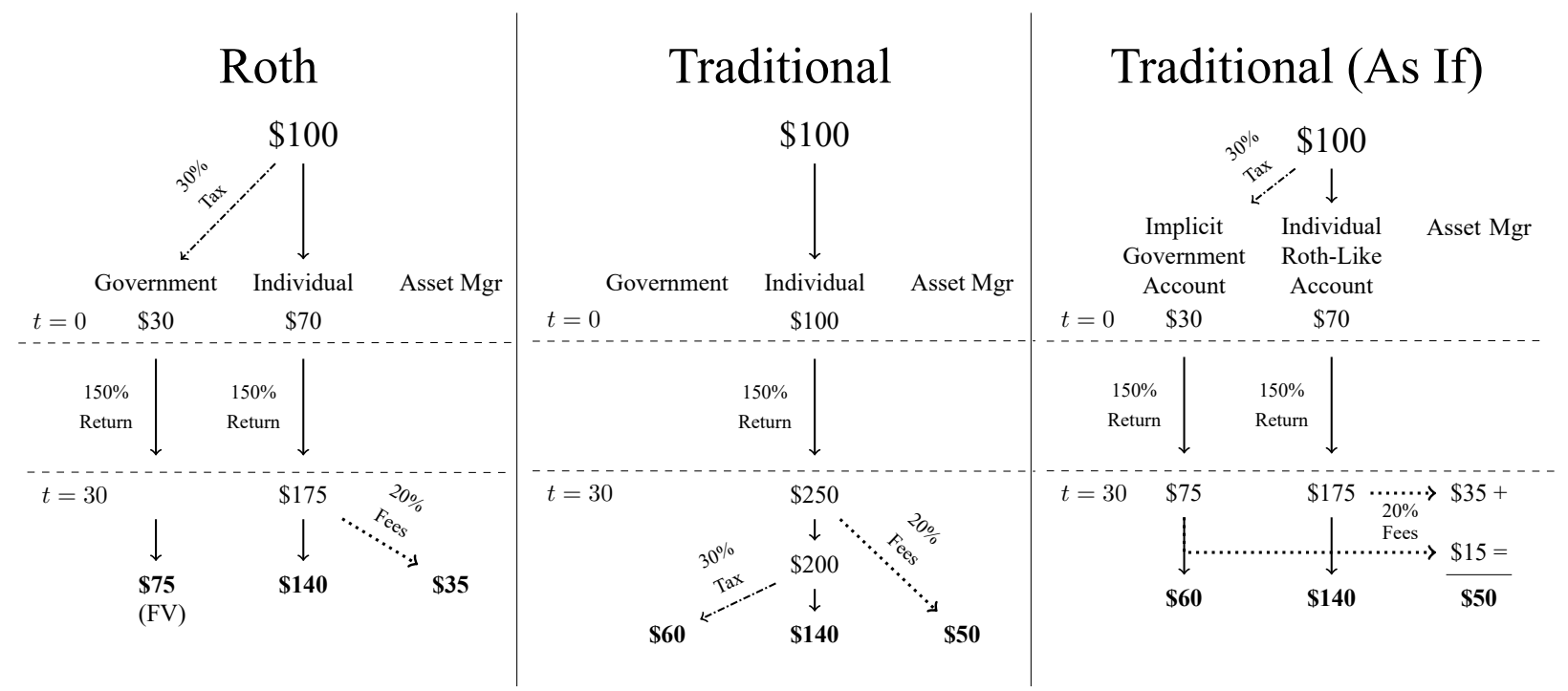

Figure 2: Fee nonneutrality. Traditional is equivalent to a Roth account plus an implicit government account equal to the balance of deferred taxes. With asset management fees, the two accounts yield the same cash flows for individuals, but the Roth account yields a superior future value (FV) for the government thanks to lower total fees. A $150 \%$ return is approximately equal to the total return on a 30 -year Treasury bond (3.10\% for 30 years); $20 \%$ fees are the future-value equivalent of $0.80 \%$ year (the value we calibrate in this paper) for 30 years.

corresponding size, our result remains: individuals' cash flows are the same under the two systems and the government incurs extra investment fees under Traditional relative to Roth. Our result is also robust to the inclusion of corporate taxes.

The fees on the government's implicit account are large. In Section 3, we produce an original, comprehensive, asset-weighted investment fee estimate of $80 \mathrm{bps}$. To do so, we start from existing industry estimates of explicit fees on DC plans and explicit asset-level fees on IRAs. We then construct our own original estimate of explicit advisory fees on IRAs. Finally, we combine academic volume-weighted estimates of trading costs with industry estimates of turnover and asset allocation to construct an asset-weighted estimate of trading costs for DC plans and IRAs. In Section 4, we estimate the size of the U.S. government's implicit account as \$3 trillion, equal to the total amount of tax-deferred assets in defined-contribution (DC) plans and IRAs ( $\$ 18.1$ trillion) times 20\%, our rough estimate of the average tax rate on retirement account withdrawals. ${ }^{6}$ We assume that $21 \%$ of

\footnotetext{
${ }^{6}$ Our estimate of assets excludes the $\$ 0.5$ trillion in the federal government's Thrift Savings Program (TSP), whose
} 
fees paid by the government are recovered via corporate taxation of the asset managers. Multiplying $\$ 3$ trillion by $.80 \% \times(1-.21)$, we reach our estimate of $\$ 20.7$ billion per year $-\mathrm{a}$ cost for the government and additional revenue to the asset management industry. ${ }^{7}$

These results, however, leave many questions open: what is the right aggregate amount of asset management services? Do the fees incurred by the government translate into cheaper or better services for individuals saving for retirement or higher profits for asset managers? How do tax rates need to adjust to balance the government's intertemporal budget constraint? In Section 5 we address questions about equilibrium fees, profits, employment in the asset management industry, tax rates, and social welfare. We present a two-period, general equilibrium model with both variable and fixed costs of asset management, and thus increasing returns to scale. Absent other frictions, economies of scale would lead to a monopoly, which is inconsistent with the large number of firms in reality. We therefore model competition among asset management firms as monopolistic competition with differentiated products and free entry (Salop, 1979). In this model, a switch from Roth to Traditional continues to increase AUM. If all costs are variable, resources devoted to asset management increase proportionally to AUM, as in our partial equilibrium model. Less obviously, resources increase even in the opposite extreme case in which all costs are fixed. In this case, firms could costlessly manage the additional assets, charge the same total dollar fees as under Roth, and leave profits unchanged, but it is profit-maximizing for them to instead increase total dollar fees. The resulting higher aggregate profits induce new firms to enter, raising the total aggregate resources devoted to asset management. Also, with logarithmic utility, our partial equilibrium assumption that percentage fees are the same under Roth and Traditional emerges endogenously in general equilibrium.

Finally, we show that a shift from Roth to Traditional in the model lowers social welfare, defined

fees are negligible. It also excludes defined-benefit (DB) plans, although a parallel argument applies to these plans as well. Including corporate and state and local government DB plans would add $\$ 7.5$ trillion of tax-deferred money, increasing our estimate of the implicit government account by $50 \%$.

${ }^{7}$ This estimate represents the cost to the government and abstracts from any potential benefits of Traditional accounts that the government receives directly (such as customized asset allocations or better performance) and indirectly (such as price discovery externalities or exposure to equity the government could not obtain otherwise). In Section 4, we discuss these potential benefits and explain why we are skeptical about their importance. 
as the aggregate utility of all individuals. By comparing the market equilibrium quantities to those chosen by a planner, we show that the Roth equilibrium in the model has too many firms (i.e., too many resources devoted to asset management) due to the "business-stealing" effect (Mankiw and Whinston, 1986), and the Traditional equilibrium has even more firms. To quantify the loss, we carry out a simple calibration exercise. Relative to Roth, Traditional in the model results in a welfare loss equivalent to roughly one percent of retirement consumption, corresponding to up to one-third of the total tax expenditure on retirement accounts. A switch from Traditional to Roth that leaves tax rates unvaried would allow the government to offer a roughly $6 \%$ match ( $\$ 6$ per $\$ 100$ of contributions) on all Roth accounts.

Our findings have important implications for the recent literature on the growth and the optimal size of finance. Recent evidence shows an upward secular trend in the size of the asset management industry as a fraction of gross domestic product (Philippon and Reshef, 2012; Greenwood and Scharfstein, 2013). We show that the growth of the government's implicit account alone may explain as much as one-fifth of the growth in conventional asset management relative to GDP since $1980 .{ }^{8}$ In our model, this part of the growth in the size of the asset management industry is inefficient. Our model also provides a simple explanation for another, related, historical trend: in spite of a large increase in scale, asset management fees have been roughly constant as a fraction of AUM (Malkiel, 2013; Philippon, 2015). Existing explanations rely on time variation in regulation, moral hazard, or information frictions (Philippon and Reshef, 2012; Bolton et al., 2016). Even in the absence of back-loaded taxation, our model shows that the assumption of monopolistic competition with differentiated products is sufficient for enhanced scale to result in firm and product proliferation instead of lower percent fees.

Our results also have implications for public policy questions related to retirement saving. The primary question is whether, given our findings, it is appropriate for the government to mandate, subsidize, or otherwise encourage a shift towards Roth accounts. Our model highlights one impor-

\footnotetext{
${ }^{8}$ Greenwood and Scharfstein (2013, Figure 2) estimate that from 1980 to 2007 the security industry's revenue grew by 3.75 percentage points of GDP. Of these, 0.95 percentage points were attributable to conventional (i.e., not alternative) asset management. In the same period, the growth in the government's tax-deferred asset raised the implicit subsidy from $0.01 \%$ to $0.10 \%$ of GDP for DC plans and IRAs (assuming constant fees of $0.80 \%$ ) and from $0.03 \%$ to $0.14 \%$ of GDP for DB plans (assuming constant fees of $0.50 \%$ ).
} 
tant advantage of Roth. However, there are potentially other important factors not captured by our model that could affect the relative desirability of the two types of account, such as progressive taxation, behavioral biases, and political economy considerations. Potential alternative policies include attempting to reduce the overall level of fees via, for example, stricter fiduciary standards for retirement savings accounts. Section 6 addresses these public policy issues and concludes.

\section{The benchmark model and the impact of fees}

In this section we begin by describing the standard equivalence result that, under some simplifying assumptions, individuals are indifferent between Traditional and Roth, and the present value of government revenue is the same. Next, we show that with fees the equivalence result remains for individuals but breaks down for the government. Finally, we argue that this result still holds when taking into account the taxation of asset managers, different tax rates during working life and retirement, and the existence of risky assets.

\subsection{Types of retirement accounts}

Money earned and saved for retirement can be taxed at three points: when earned (labor income), as returns are generated (investment income), and when paid out of the account in retirement (account withdrawals). We assume three proportional tax rates, one for labor income $\left(\tau_{L}\right)$, one for intermediate investment returns $\left(\tau_{I}\right)$, and one for retirement income $\left(\tau_{R}\right)$. Tax rates do not vary, either across time or with the level of income, and we abstract from details such as contribution limits, withdrawal penalties, and required minimum distributions. ${ }^{9}$

\footnotetext{
${ }^{9}$ In practice, the tax system is instead progressive (i.e., marginal tax rates increase with income), so that even if the tax rate schedule is constant over time, a lower level of income in retirement would imply $\tau_{L}>\tau_{R}$. This is our main motivation for allowing distinct tax rates. Progressivity also introduces additional complications: when coupled with uncertain labor income or asset returns, marginal tax rates become stochastic. In addition, Roth accounts have less restrictive effective contribution limits (Burman et al., 2001) and fewer restrictions on withdrawals. We also ignore for now any behavioral factors that could cause individuals to choose a consumption plan that differs from the optimum computed here under one or both accounts. We discuss some of these factors in the conclusion.
} 


\begin{tabular}{lccccc}
\hline $\begin{array}{c}\text { Account } \\
\text { type }\end{array}$ & Label & $\begin{array}{c}\text { Type } \\
\text { of } \\
\text { taxation }\end{array}$ & $\begin{array}{c}\text { Tax on } \\
\text { initial } \\
\text { contribution }\end{array}$ & $\begin{array}{c}\text { Tax rate } \\
\text { on investment } \\
\text { returns }\end{array}$ & $\begin{array}{c}\text { Tax on } \\
\text { retirement } \\
\text { payouts }\end{array}$ \\
\hline Taxable & TTE & Front-loaded & $\tau_{L}$ & $\tau_{I}$ & 0 \\
Traditional & EET & Back-loaded & 0 & 0 & $\tau_{R}$ \\
Roth & TEE & Front-loaded & $\tau_{L}$ & 0 & 0 \\
\hline
\end{tabular}

Table 1: Different tax treatment of retirement savings.

Table 1 compares three possible account types: a common taxable account (Taxable), backloaded taxation (Traditional) and front-loaded taxation (Roth). Based on the timing of taxation, these accounts are also conventionally referred to as TTE, EET, and TEE, respectively. For instance, a common taxable account is TTE because earned income is taxable, investment returns are taxable, but account distributions in retirement are exempt.

\subsection{Benchmark equivalence result}

A representative individual saves $S$ in a Traditional or Roth account. We assume that the individual has the same pretax labor earnings $Y$ under either account type. We also assume that the tax rates are the same under Traditional and Roth (i.e., $\tau_{L}^{\text {Roth }}=\tau_{L}^{\text {Trad }}=\tau_{L}$ ), an assumption we relax later in our general equilibrium analysis. Finally, we assume the account assets earn a fixed non-stochastic return of $r .^{10}$

Under these assumptions, a standard equivalence result holds (e.g. Brady, 2012): if $\tau_{R}=\tau_{L}$, then any choice of initial consumption $\left(C_{0}^{\text {Trad }}=C_{0}^{\text {Roth }}=C_{0}\right)$ will generate retirement consumption that is the same under Roth as under Traditional. To see this, note that Traditional results in a larger account size: $S^{\text {Roth }}=Y\left(1-\tau_{L}\right)-C_{0}$, and $S^{\text {Trad }}=\left[Y\left(1-\tau_{L}\right)-C_{0}\right] /\left(1-\tau_{L}\right)$, so that $S^{\text {Roth }} / S^{\text {Trad }}=1-\tau_{L}$. Next, define $C_{T}$ as final consumption (equal to terminal wealth after $T$ years). Since $C_{T}^{\text {Roth }}=S^{\text {Roth }}(1+r)^{T}$ and $C_{T}^{\text {Trad }}=\left[S^{\text {Trad }}(1+r)^{T}\right]\left(1-\tau_{R}\right)$, then $C_{T}^{T r a d} / C_{T}^{R o t h}=\left(1-\tau_{R}\right) /\left(1-\tau_{L}\right)=1$. Since the set of all feasible consumption plans is the

\footnotetext{
${ }^{10}$ Formally, we assume a linear storage technology, with storage allowed to be positive or negative. The individual invests her assets in this storage technology or in riskless government bonds (which, by no-arbitrage, yield $r$ as well).
} 


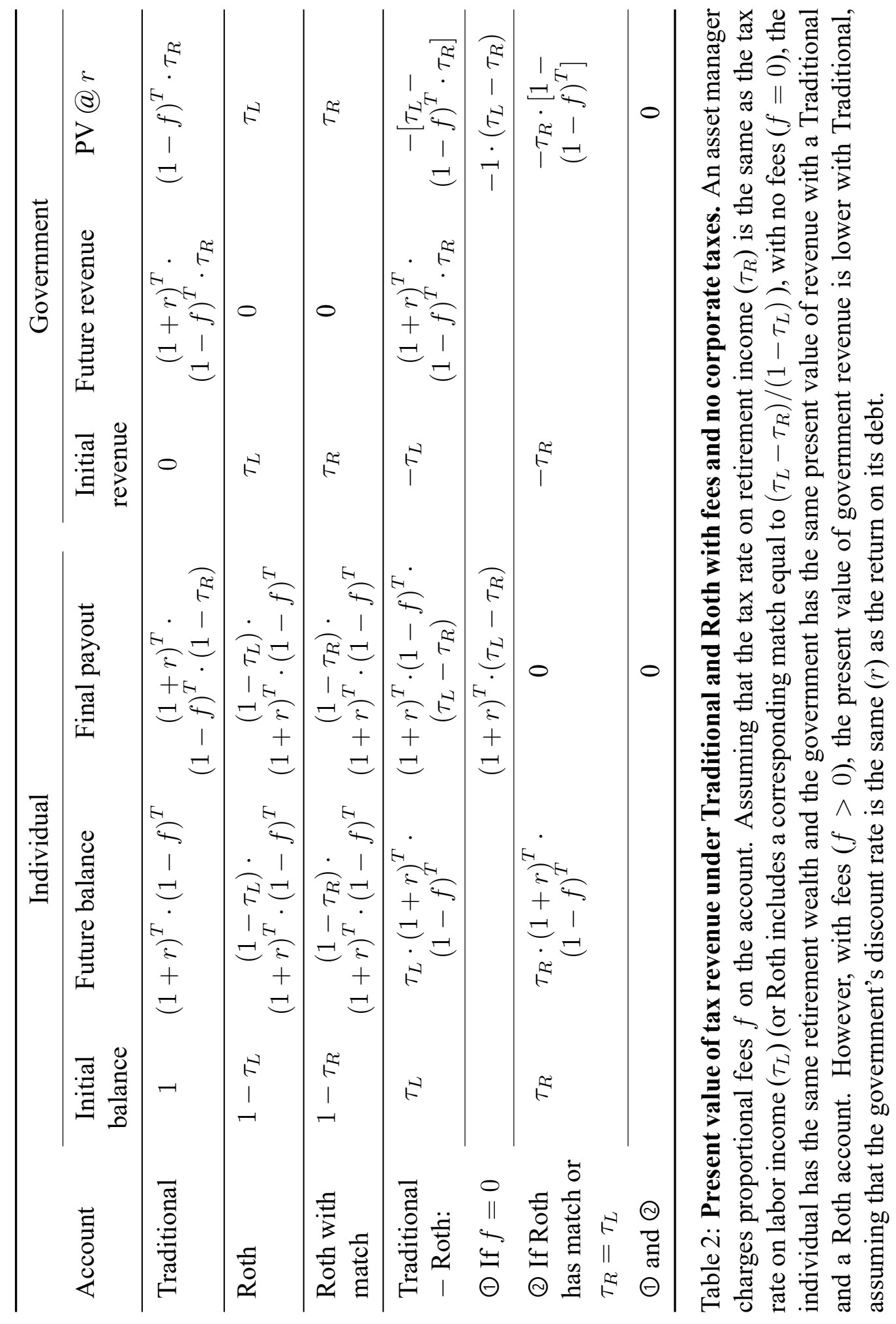


same under Roth and Traditional, it must be the case that the individual's optimal consumption plan (i.e. both initial and retirement consumption) is the same under the two systems. The government's cash flow differs across plans - revenue is received up front with Roth accounts and deferred with Traditional. However, assuming that the government's discount rate is equal to the interest rate on government bonds, it is easy to show that the present value of government revenue is $Y \cdot \tau_{L}$ under both systems. ${ }^{11}$

\subsection{Adding fees}

Next, we assume that at time 0 an asset management firm charges fees equal to a fixed proportion $f$ of the value of retirement account assets. The assumption that percentage fees are fixed can be interpreted in several ways. For instance, it could hold exactly if the total cost of producing asset management services were proportional to aggregate assets and firms set fees equal to marginal costs. Another possibility is that the economy is a small open economy, and any changes in the assets are immaterial for the scale at which asset managers operate. In Section 5, we obtain this fixed percentage fees result endogenously in a more complex model with fixed and variable costs. We assume initially that the government does not tax the corporate income of asset managers $\left(\tau_{C}=0\right)$.

Table 2 shows the initial and future cash flows for both the individual and the government. We normalize the initial account size under Traditional to be $\$ 1$, which can be funded with $\$ 1$ of pre-tax income. With a Traditional account, the government has no revenue upfront, and the individual's account balance is 1 . At time $T$, when the individual retires and the account is liquidated, the balance, $(1+r)^{T}(1-f)^{T}$, is paid out and taxed. The government receives a fraction $\tau_{R}$ of the balance, and the individual receives the remaining fraction $1-\tau_{R}$. With a Roth account, $\$ 1$ of pre-tax income pays for an account contribution of $1-\tau_{L}$ and yields immediate tax revenue of $\tau_{L}$.

\footnotetext{
${ }^{11}$ Even if $r$ were determined endogenously, i.e. if the storage technology did not exist, a shift from Roth to Traditional would leave $r$ and all consumption allocations unchanged. For every dollar in a Traditional account, the government faces a revenue shortfall relative to Roth of $\tau_{L}$, and so must issue an extra amount $\tau_{L}$ of bonds, adding to the existing supply. At the same time, the account balance is $\tau_{L}$ larger relative to Roth. Since the account is invested in government bonds, this creates additional demand for government bonds equal to $\tau_{L}$. Thus, the higher desired private saving is exactly offset by the lower government saving, leaving desired national savings and the equilibrium interest rate the same under Traditional and Roth.
} 
No subsequent taxation happens, and therefore at time $T$ the individual keeps the entire balance, $\left(1-\tau_{L}\right)(1+r)^{T}(1-f)^{T}$.

If $\tau_{R}=\tau_{L}$, a necessary condition for the benchmark equivalence result, any choice of initial consumption will again generate the same retirement consumption under Roth as under Traditional. The individual will therefore choose the same consumption path under Roth as under Traditional and be indifferent between the two. ${ }^{12}$ This is shown in the two bottom rows of Table 2. With $f>0$, however, the government has unambiguously lower present value of tax revenue under Traditional: $\mathbf{P V}\left(\right.$ Tax Revenue $\left.{ }^{\text {Trad }}\right)-\mathbf{P V}\left(\right.$ Tax Revenue $\left.{ }^{\text {Roth }}\right)=-\tau_{R}\left[1-(1-f)^{T}\right]<0$. This formula has an intuitive interpretation: $\tau_{R}$ is the initial size of the government's implicit account under Traditional, and $1-(1-f)^{T}$ is the fraction of the account that gets eroded by fees. Due to this revenue loss, if the government's present value budget constraint holds under Roth, it no longer holds under Traditional. ${ }^{13,14}$

Taxing the income of asset managers at a rate $\tau_{C}$ shrinks, but does not eliminate, the present value loss in tax revenue. We assume for simplicity that all costs are fixed, so that every extra dollar of asset manager revenue turns into an extra dollar of pretax profits and an extra $\tau_{C}$ dollars of tax revenue. ${ }^{15}$ Then, the government receives a stream of corporate tax revenues growing at the same rate as the account balance, effectively recapturing a fraction $\tau_{C}$ of the fees paid on its implicit account. The PV of government revenue entry in Table 2 then becomes

$$
\text { PV }\left(\text { Tax Revenue }{ }^{T r a d}\right)-\mathbf{P V}\left(\text { Tax Revenue }{ }^{\text {Roth }}\right)=-\tau_{R}\left[1-(1-f)^{T}\right]\left(1-\tau_{C}\right) .
$$

\footnotetext{
${ }^{12}$ Note that since the after-fee rate of return on the accounts is now lower than without fees, the optimal choice of saving and consumption with fees can differ from the no-fee case.

${ }^{13}$ Here we ignore the implications of this budget deficit for taxes. We address this issue later in our general equilibrium model of Section 5, in which equilibrium tax rates are higher under Traditional.

${ }^{14}$ The additional assets under management under Traditional generate higher fees. While in Table 2 all of the added fees under Traditional are borne by the government, alternative assumptions about the deductibility of fees could shift some or all of the burden to individuals. In Section 2 of the Internet Appendix, we examine four types of accounts. In addition to standard Roth accounts (in which fees are non-deductible) and standard Traditional accounts (in which fees are effectively deductible), we consider two hypothetical accounts: a "fee-deductible Roth", in which individuals receive a deduction for fees, and a "fee-nondeductible Traditional", in which the government taxes the individual based on the gross-of-fees balance. We thank Mariacristina DeNardi for suggesting we examine the latter account type.

${ }^{15}$ If the additional assets result in additional costs, only a fraction of the revenue turns into profits for the asset manager. However, most asset manager costs would equal taxable income for employees (e.g. additional hours worked) or other entities connected with the asset manager (e.g. additional bid-ask spreads and fees paid to a broker-dealer). We abstract from these complexities.
} 


\subsection{Adding unequal tax rates}

Next we consider the case $\tau_{R} \neq \tau_{L}$ (for simplicity returning to $\tau_{C}=0$ ). Under this assumption, even if $f=0$, the benchmark equivalence does not hold. However, we can now decompose each dollar of a Traditional account balance into three virtual accounts as follows:

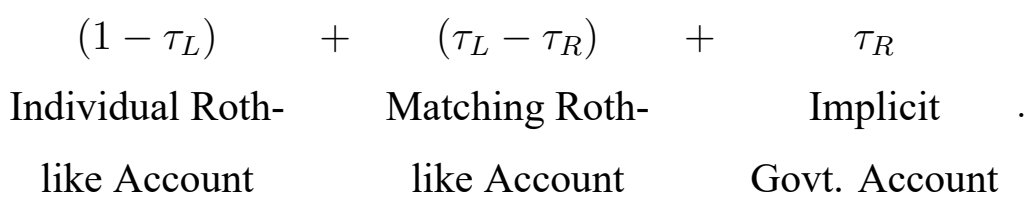

As in Figures 1 and 2, the first term is a "Roth-like" account of size $1-\tau_{L}$, as if the individual had contributed to a Roth account, and the third term is the "implicit government account" of size $\tau_{R}$ that represents the claim the government has due to future taxes when the investor takes distributions from the account. The middle term is new, and represents a "matching Roth-like account" of size $\tau_{L}-\tau_{R}$, the difference in tax rates between labor income and retirement income. This account is akin to an employer matching program - the government matches every dollar the individual puts in the Roth-like account with a grant of $\left(\tau_{L}-\tau_{R}\right) /\left(1-\tau_{L}\right)$, yielding a total grant of $\tau_{L}-\tau_{R}$. The difference between the PV of government revenue under Traditional and Roth in Table (2) can be rewritten as $\mathrm{PV}\left(\right.$ Tax Revenue $\left.{ }^{\text {Trad }}\right)-\mathrm{PV}\left(\right.$ Tax Revenue $\left.{ }^{R o t h}\right)=-\tau_{R}\left[1-(1-f)^{T}\right]-\left(\tau_{L}-\tau_{R}\right)$, equal to the extra fees that the government pays under Traditional on its implicit account plus the cost of the match. If $\tau_{R}<\tau_{L}$, the match is positive and therefore individuals prefer Traditional to Roth and also face a stronger incentive to postpone consumption. The government, on the other hand, must pay for the match and therefore has a lower PV of revenue under Traditional. If $\tau_{R}>\tau_{L}$, there is a negative implicit match and the results are reversed.

If, under Roth, the government were to add an explicit match on the Roth account of $\tau_{M}^{\text {Roth }}=$ $\left(\tau_{L}-\tau_{R}\right) /\left(1-\tau_{L}\right)$ per dollar of contribution, then our results that held when $\tau_{R}=\tau_{L}$ would continue to hold even with $\tau_{R} \neq \tau_{L}$. Specifically, comparing Roth-with-explicit-match to Traditional, individuals would have identical cash flows, and the present value of government revenue would be lower under Traditional by $\tau_{R}\left[1-(1-f)^{T}\right]$, due to the extra fees the government pays on its 
implicit account.

\subsection{Adding a risky asset}

So far we have assumed that there is only one asset in the economy: government bonds. In reality, however, roughly two-thirds of the government's $\$ 3$ trillion implicit account is invested in stocks, mostly through actively and passively managed stock funds. Consider the base case above with $\tau_{R}=\tau_{L}$, but now suppose that there are two assets: the government bond yielding $r$ and a risky asset (stocks) that has a stochastic return $\widetilde{r}_{s}$ and expected return $r_{s}>r$. Individuals choose the share $a$ of the portfolio that is held in stocks.

Holding tax and rates of return constant, and for the moment ignoring fees, it is straightforward to show that the individual would be indifferent between Roth and Traditional: under either system, the individual would choose the same initial consumption and portfolio share $a$, and thus identical (risky) future consumption. As before, the timing of the government's cash flows differs between Roth and Traditional, but now the incremental delayed cash flows under Traditional are positively correlated with realized stock returns, and thus have both higher expected value and higher risk than in the benchmark case. ${ }^{16}$ A shift from Roth to Traditional is now equivalent to an increase in the supply of government bonds, an equal increase in the private demand for government bonds in the government's implicit account, and a portfolio swap in that account that raises the demand for stocks and lowers the demand for bonds.

If the government faces no binding constraints on its holdings of stocks, then the appropriate rate for discounting the expected cash flows from the government's implicit stockholdings will be $r_{s}$, and so the present value of tax revenues will continue to be the same under the two systems and the benchmark equivalence result will continue to hold.

The government could be constrained under Roth from holding more stocks, for example due to political constraints as democracies are usually averse to direct government holdings of productive

\footnotetext{
${ }^{16}$ Under Roth, the tax revenue is $\tau$ at time 0 . Under Traditional, the tax revenue at time $T$ is a random variable equal to $\left[a\left(1+\widetilde{r}_{s}\right)^{T}+(1-a)(1+r)^{T}\right] \tau$. The expected tax revenue is equal to $\left[a\left(1+r_{s}\right)^{T}+(1-a)(1+r)^{T}\right] \tau$, which is increasing in $a$.
} 
assets (see, e.g., Che and Qian, 1998). ${ }^{17}$ If the government faced such a constraint, and it were binding, then the value of an extra dollar of stock due to a shift from Roth to Traditional would be based on a discount rate $r_{s}^{\prime}$, lower than the equilibrium discount rate $r_{s}$, for a hypothetical marginal benefit of the shift equal to approximately $r_{s}-r_{s}^{\prime} .{ }^{18}$ However, it is not clear that such a constraint, even if present, would necessarily be binding. The government already has substantial implicit exposure to equities through the tax system due to the positive correlation between tax revenue cash flows and stock market performance, and it may not be advantageous for it to increase this exposure further (Auerbach, 2004). In this scenario, the government could even face a binding constraint under Traditional that precluded it from reducing its equity exposure, which would imply $r_{s}-r_{s}^{\prime}<0$. A full analysis would require a general equilibrium model and a complete specification of the nature of the constraints. The issues that arise here are similar to those in the literatures on whether the Social Security trust fund should invest in equities. ${ }^{19}$

How is the government's optimization problem influenced by the presence of investment fees? In the absence of constraints, the government could likely replicate the implicit government stock holdings under Traditional with a much less expensive combination of a Roth system and a sovereign wealth fund. An investment management firm could manage a largely passive portfolio that could mimic the holdings of aggregate retirement accounts (or the aggregate stock market) at the likely cost of only a few basis points. If, however, the government faced political or other constraints on direct stock holdings, then one would need to compare the benefits from the added stock holdings

\footnotetext{
${ }^{17}$ These constraints are not universal, however, as some governments do hold trillions of dollars of professionally managed risky investments via sovereign wealth funds. At the time of writing, the Sovereign Wealth Fund Institute (https://www.swfinstitute.org/sovereign-wealth-fund-rankings/, visited on 12/9/2019) places total sovereign wealth fund assets at \$8 trillion. Holdings of risky assets vary by fund, but as of Q3 2019 Norway's Government Pension Fund Global, the world's largest sovereign wealth fund, held 69.1 percent of its assets in equities (https://www.nbim.no/en/the-fund/market-value/).

${ }^{18}$ If the government is constrained, then its intertemporal budget constraint will no longer be satisfied in some or all states of the world after a switch from Traditional to Roth or vice versa. If future taxpayers see fully through the government veil, it is possible that a "super" Ricardian equivalence result could hold in general equilibrium. This would require future taxpayers under Traditional to realize that the government will have to change taxes in the future based on realized stock returns up to then. This tax policy would amount to an implicit stock position for individuals, who would reduce their own stock holdings today. In this scenario, demand and supply of stocks and bonds could remain in balance with no change in interest rates, stock expected returns, or household consumption.

${ }^{19}$ See, for example, Bohn (1990), Geanakoplos et al. (1999), Abel (2001), Diamond and Geanakoplos (2003), and Lucas and Zeldes (2009). See also the related discussion in Romaniuk (2013).
} 
under a Traditional system (relative to Roth) to the loss from the higher fees paid on the extra assets held in retirement accounts. ${ }^{20}$

\section{Investment fees $(f)$}

In this section we produce an original, comprehensive, asset-weighted estimate of explicit fees (both asset-level and account-level) and trading costs for DC plans and IRAs. Weighting by assets is necessary for our purposes because lower-cost funds tend to have more AUM (Hubbard et al., 2010). However, most published estimates of mutual fund fees and overall net-of-fees performance are equal-weighted at the fund level in order to measure average fund quality or average manager skill. Similarly, most published estimates of trading costs are volume-weighted in order to measure trader execution skill or overall market liquidity.

We start from existing industry estimates of explicit fees on DC plans and explicit asset-level fees on IRAs. We then construct our own original estimate of explicit advisory fees on IRAs. Finally, we combine academic volume-weighted estimates of trading costs with industry estimates of turnover and asset allocation to construct an asset-weighted estimate of trading costs for DC plans and IRAs. Our overall estimate of $f$ is 80 basis points (bps), obtained as the asset-weighted average of 65 bps for DC plans and 92 for IRAs. Our results are summarized in Table 3 and described in more detail below. Additional detail on fees, transaction costs, and net-of-fees performance is provided in Section 3 of the Internet Appendix.

\subsection{Explicit fees}

An individual saving for retirement faces at least two types of explicit fees: asset-level fees and account-level fees. Asset-level fees are charged based on what financial products the account

\footnotetext{
${ }^{20}$ Note that the entire balance in the government account (bonds and stocks) pays fees at a rate $f$, but only a fraction $a$ is invested in stocks, for a cost $f / a$. Thus, $r_{s}-r_{s}^{\prime}>f / a$ is required for the first dollar of additional equity exposure to be beneficial. For instance, with fees equal to $0.80 \%$ (our asset-weighted estimate), $a=2 / 3$ (a value close to the actual asset allocation of U.S. retirement accounts) and an expected return on stocks of $8 \%$, the government's discount rate on the marginal dollar of stocks would need to be at least $1.2 \%(=0.80 /(2 / 3))$ lower than the expected return on stocks in order for the benefits of a marginal shift to Traditional accounts to outweigh the costs.
} 
Panel A. Overall Fee Breakdown (bps).

\begin{tabular}{|c|c|c|c|c|}
\hline Tax-Deferred Assets & \multicolumn{2}{|c|}{$\begin{array}{l}\text { 1. Explicit Fees } \\
\text { Account Fees, Exp. } \\
\text { Ratios, Distr. Fees }\end{array}$} & $\begin{array}{l}\text { 2. Trading Costs } \\
\text { Commissions, } \\
\text { Bid/Ask, Mkt. Impact }\end{array}$ & $\begin{array}{c}\text { Total } \\
{[1+2]}\end{array}$ \\
\hline A. DC Plans ( $\$ 7.8$ trillion) & All-in fees & $50^{*}$ & $15^{\dagger}$ & 65 \\
\hline B. IRAs ( $\$ 9.7$ trillion) & $\begin{array}{l}\text { Asset-level fees } \\
\text { Advisory fees }\end{array}$ & $\begin{array}{l}36^{*} \\
41^{\ddagger}\end{array}$ & $14^{\dagger}$ & 92 \\
\hline Weighted Average (A, B) & & 65 & 14 & 80 \\
\hline
\end{tabular}

(*) Based on Deloitte and BrightScope/ICI studies (Rosshirt et al., 2014; BrightScope and ICI, 2019); ( $\dagger$ ) estimate derived from volume-weighted academic estimates of trading costs using industry estimates of fund turnover; ( $\$$ ) original estimate based on SEC 10K filings. Rows may not add up to totals because of rounding.

Panel B. Asset-Level Fees and Trading Costs Breakdown (bps).

\begin{tabular}{|c|c|c|c|c|c|c|}
\hline & & DC & & & RAs & \\
\hline & Asset & Alloc. & Trading & Alloc. & Asset & Trading \\
\hline & Class & & Costs & & Fees & Costs \\
\hline & Equity & $50 \% \diamond$ & $15^{\S}$ & $26 \%{ }^{*}$ & $66^{*}$ & $15^{\S}$ \\
\hline$z$ & Bonds & $10 \% \diamond$ & $27^{\S}$ & $8 \%{ }^{*}$ & $49^{*}$ & $27^{\S}$ \\
\hline Е & Balanced ${ }^{* *}$ & $24 \% \diamond$ & $20^{\S}$ & $10 \%{ }^{*}$ & $65^{*}$ & $20^{\S}$ \\
\hline & Cash & $3 \% \diamond$ & $0^{\wedge}$ & $3 \%{ }^{*}$ & $25^{\dagger}$ & $0^{\wedge}$ \\
\hline 0 & Equity & & - & $27 \%{ }^{*}$ & & $15^{\infty}$ \\
\hline ?2. & Bonds & $0^{\wedge}$ & - & $8 \% *$ & $0^{\wedge}$ & $27^{\alpha}$ \\
\hline & Cash & & - & $6 \% *$ & & $0^{\wedge}$ \\
\hline & Other" & $8 \%^{*}$ & $67^{\dagger}$ & $13 \%^{*}$ & $67^{\dagger}$ & \\
\hline & Own stock & $5 \% *$ & $0^{\wedge}$ & & & \\
\hline & Average & & 15 & & 36 & 14 \\
\hline
\end{tabular}

(*) Our estimation based on ICI, EBRI, and Deloitte data (Rosshirt et al., 2014; ICI, 2019;

Copeland, 2018); (†) Reported in (BrightScope and ICI, 2019), IRA assumed same as DC; $\left(^{\wedge}\right)$ Assumed negligible; (§) Based on academic estimates of volume-weighted costs (Anand et al., 2012 and Busse et al., 2018 for equity; Bessembinder et al., 2018, Choi and Huh, 2017, and Goldstein and Hotchkiss, 2018 for bonds) and industry turnover estimates (BrightScope and ICI, 2019 for equity; Rowley and Dickson, 2012 and Novick et al., 2016 for bonds); ( $\diamond)$ Based on ICI research (Holden et al., 2019; ICI, 2019); ( $\propto$ ) assumed same as funds; (**) assumed to be $60 \%$ equity and 40\% bonds. (9) "Other" assets include real estate assets, fixed and variable annuities, and any remaining assets that do not fit into equities, bonds, money or balanced funds.

Percentages may not add up to $100 \%$ because of rounding.

\section{Table 3: Overview of our estimates of investment fees and costs.}


money is invested in, and include both ongoing fees (mutual fund expense ratios) and one-time fees (front or back-end loads). Some of these fees are paid to asset managers (e.g., mutual fund sponsors, insurance companies, and issuers of structured notes) and some (typically revenue from sales loads and/or 12b-1 fees that are included in the expense ratio) are paid to distribution channels (e.g., mutual fund brokers, securities brokers, and advisors to 401(k) plans).

Account-level fees include account maintenance fees in IRAs and DC plans charged by the recordkeeper or account provider, typically as a fixed dollar amount per account. They also include advisory fees charged by financial advisers for providing expertise to individuals in asset allocation, estate and tax planning, and other services covering one or multiple accounts belonging to the same individual or household. These fees, sometimes also referred to as "wrap" fees, are generally charged as a percent of the total value of advised assets.

For DC plans (row 1, column 1), we rely on two asset-weighted estimates made by industry participants in partnership with the industry trade association, the Investment Company Institute. Both estimates focus on 401(k) accounts, and thus exclude 403(b) and other plan types, and they also focus on the largest and most efficient plans. Deloitte (Rosshirt et al., 2014) estimates the "allin fee" at 58 bps, while BrightScope (2019) estimates "total plan costs" at 39 bps. ${ }^{21}$ Because the BrightScope study excludes about $\$ 1$ trillion or $27 \%$ of total assets held in the smallest, and likely most expensive, plans, we put somewhat more weight on the Deloitte estimates. We calculate our estimate as a weighted average of Deloitte (60\%) and BrightScope (40\%), resulting in an estimate of total account and asset-management fees of $50 \mathrm{bps}$.

Next we consider explicit fees on IRAs (row 2, column 1). IRA asset-level fees are estimated as an asset-weighted average by type of product (mutual funds, individual securities, and other) and asset class (stocks, bonds, money markets, and other) based on industry estimates. As shown in Panel B of the table, about $41 \%$ of IRA assets is invested in individual securities or cash without explicit fees other than trade commissions, about $46 \%$ is held in mutual funds with asset-weighted

\footnotetext{
${ }^{21}$ The BrightScope estimate is based on filings by audited plans, which generally means plans with 100 or more participants. The Deloitte estimate is survey-based excluding plans with less than $\$ 1$ million in assets and oversampling large plans, yielding representation of roughly $97 \%$ of the assets (36\% of the plans) within the universe of plans filing Form 5500 with the Department of Labor.
} 
average fees of $60 \mathrm{bps}$, and the remaining 13\% is invested in other products like real estate funds, commodity funds, etc. whose fees are estimated at $67 \mathrm{bps} .^{22}$ This yields an asset-weighted estimate of IRA asset-level fees of $36 \mathrm{bps}$.

IRA account-level fees, particularly advisory fees, are challenging to estimate. There is no systematic source of information on what fraction of investors participate in programs of paid advisory services or on the size of the fees paid by those who participate, and to the best of our knowledge no comprehensive estimate of these fees is available. We construct original "supply-side" estimates of account-level AUM-based advisory fees by relying on SEC filings and other publicly available information. Most of the largest IRA providers are exchange-listed discount brokers, mutual fund families, and the retail arms of large banks and insurance companies, who disclose the relevant information in their annual reports (SEC 10K forms). Using industry sources, we identify the top 20 IRA account providers by 2019 assets under administration. For 18 of the top 20 (corresponding to $74.9 \%$ of total IRA assets and $97.9 \%$ of top-20 assets), we are able to estimate percent advisory fees as total revenue from AUM-based advisory programs divided by total client assets, regardless of assets actually enrolled in fee-based advisory programs. ${ }^{23}$ We estimate average IRA advisory fees to be 41 bps (see Table 4 for this estimate and more information on its derivation).

\footnotetext{
${ }^{22}$ Average mutual fund fees in IRAs (60 bps) are estimated using IRA-specific asset allocations and expense ratios from the ICI (Holden et al., 2019; ICI, 2019). This figure is higher than mutual funds held in DC plans (45 bps, analogously estimated) due mainly to distribution fees. The asset allocation for individual securities is inferred by crossing the same ICI data with EBRI data on overall IRA asset allocation (Copeland, 2018). Having no IRA-specific data on money-market funds and "other" investments, we use the corresponding DC plan figures (25 bps and 67 bps respectively) reported by BrightScope and ICI (2019). The assumption of no fees for individual securities is conservative, because some of these securities may be structured notes, known for their high implicit fees (Carlin, 2009; Henderson and Pearson, 2011). More information on sources is in the table caption.

${ }^{23}$ For instance, if half of the clients pay $100 \mathrm{bps}$ in advisory fees and the other half does not use a fee-based advisor, our methodology produces an estimate of $50 \mathrm{bps}$. Note that we exclude from revenue any distribution-related fees, which are already counted as part of asset-level fees. Two providers are large, privately held mutual fund families. For one, we are able to obtain the relevant information from press reports, and for the other we simply use the average of publicly held mutual fund families and discount brokers. Finally, two nonprofit providers are excluded because we are not able to obtain the relevant information.
} 


\begin{tabular}{lcccc}
\hline \multirow{2}{*}{ IRA provider type } & \multicolumn{2}{c}{ Market share } & Advisory Fee & No. \\
\cline { 2 - 3 } Revenue (bps) & Firms \\
\hline Full-service broker or MF family & $36.9 \%$ & $48.2 \%$ & 57 & 10 \\
Discount broker or MF family & $35.6 \%$ & $46.5 \%$ & 16 & 6 \\
Insurance company & $2.4 \%$ & $3.1 \%$ & 166 & 2 \\
\hline Total & $74.9 \%$ & $97.9 \%$ & 41 & 18 \\
\hline
\end{tabular}

Table 4: Estimates of advisory fees in IRAs. Advisory fee revenue is measured as total advisory and brokerage account revenue as a fraction of total client assets, advised and non-advised (see footnote 23). Full-service brokers are large banks with a wealth management arm. Full-service mutual fund (MF) families are firms that hold a substantial fraction of assets under management in actively managed mutual funds. Discount brokers are companies that offer a brokerage account and a simple set of tools to manage one's portfolio, and discount mutual fund families are firms that offer predominantly low-cost index funds.

\subsection{Trading costs}

Both collective investment funds and individual investors who directly trade individual securities pay trading commissions and bid-ask spreads. Trading commissions are not included in the expense ratio of mutual funds (Livingston and Zhou, 2015). Funds also incur costs due to market impact, defined as adverse price moves caused by one's trades. Because of their size, unique disclosure requirements, and liquidity needs, mutual funds trade more predictably than other investors; as a result, they can be front-run and face adverse price pressure (Ben-Rephael et al., 2011; Shive and Yun, 2013). Predictability is especially a problem for index funds who trade mechanically to rebalance and incorporate changes in the index (Pedersen, 2018), even though overall their trading costs are lower than active funds because they trade less and their uninformed trading generates less market impact. Market impact and bid-ask spreads are not straightforward to assess even for the fund itself, and they are rarely if ever disclosed, but they are reflected in returns. ${ }^{24}$

We first estimate asset-weighted trading costs at the asset class level, and then we construct

\footnotetext{
${ }^{24}$ To further complicate the picture, some broker-dealers offer "soft-dollar" arrangements under which they provide clients (i.e., funds) with services such as research reports in exchange for their business (Conrad et al., 2001; Livingston and Zhou, 2015). These arrangements do not change the total of explicit expenses plus implicit trading costs, and thus do not affect our final fee estimate. However, they reduce the funds' explicit expenses to the detriment of execution quality (i.e. higher trading costs), and thus muddy the distinction between explicit fees and trading costs.
} 
separate estimates for IRAs and DC plans using their respective asset allocations. We estimate annual trading costs based on a standard approximation formula (trading costs per unit of volume $\times 2 \times$ annual turnover). Trading costs per unit of volume are measured as explicit commissions plus execution shortfall, a standard volume-weighted measure of execution quality, defined as the difference between the actual execution price and a reference price observed at the time the order is placed. Turnover is defined as the lesser of a fund's gross purchases and sales of securities divided by the fund's average net assets, so that $2 \times$ annual turnover is a lower bound to total volume of trading as a fraction of total fund assets.

For stock funds, recent estimates place trading cost at roughly 26 basis points per unit of volume (Anand et al., 2012; Busse et al., 2018). The average turnover of U.S. equity funds (active and passive combined) is $32 \%$, but only $28 \%$ for mutual funds held in $401(\mathrm{k})$ accounts (BrightScope and ICI, 2019) because of a greater prevalence of low-turnover index funds. Assuming the latter figure applies to both DC plans and IRAs, we obtain annual trading costs for equity mutual funds of $28 \times 2 \times 26 \%=15 \mathrm{bps}$, lower than typical pronouncements by industry insiders. ${ }^{25}$

For bond funds, we conservatively use cost estimates for the largest corporate bond trades. Unlike in the case of stocks, large bond transactions have a lower cost per unit of volume, suggesting that execution shortfall is driven less by market impact and more by search frictions. A recent, comprehensive estimate (Bessembinder et al., 2018, Table III) places transaction costs on corporate bond trades of \$5 million and up in the 2012-2014 period at roughly 17 bps of trade size for a round-trip, or 8.5 bps per unit of volume, consistent with other recent works (Choi and Huh, 2017; Goldstein and Hotchkiss, 2018).

Assessing turnover for bond funds is less straightforward than for stock funds. Vanguard (Rowley and Dickson, 2012) estimates that the asset-weighted average portfolio turnover of open-end bond funds ranges from $90 \%$ for index funds to 193\% for active funds. Using AUM figures from Blackrock (Novick et al., 2016) we calculate asset-weighted average turnover of $178 \%$, reflecting

\footnotetext{
${ }^{25}$ A managing director for Morningstar (Phillips, 2013) states that in the five years prior to March 31, 2013 "the average U.S. large-cap equity fund, on an asset-weighted basis, trails the market index by its expense ratio plus ... 25 basis points." Bogle (2014) guesstimates trading costs of $50 \mathrm{bps}$ for active equity funds, and negligible for passive equity funds. Taken at face value, and assuming that active funds' market share is equal to their overall U.S. market share (roughly $50 \%$ ), Bogle's figures imply asset-weighted trading costs of roughly 25 bps.
} 
the predominance of active funds. We multiply this turnover by 1.8 , rather than by 2 , to reflect the fact that some reported turnover may be driven by reinvestment of coupon and principal payments, rather than sales and purchases. ${ }^{26}$ Thus, our estimate of trading costs for bond funds is $8.5 \times 1.8 \times 178 \%=27$ bps.

Thus, our estimate of trading costs is 15 bps for equity funds, 27 bps for bond funds, and 0 bps for money market funds, own-company stock and other investments. For individual securities, in the absence of data, we assume the same trading costs in each of the three corresponding asset classes. Based on the overall asset allocation in DC plans and IRAs shown in Table 3, we estimate total asset-weighted implicit trading costs of 15 bps and 14 bps respectively.

\section{Calibration: the subsidy to asset managers under Traditional}

We estimate the total size of the subsidy under Traditional as the payment from the government to asset managers that would not exist under Roth. We use several simplifications. First, as in equation (1) from Section 2, we ignore the "match" (i.e., we assume $\tau_{L}=\tau_{R}$ ). Second, we focus on the annual flow of revenue being lost to fees rather than the present value of all foregone revenue, because we want to measure the subsidy and its impact in a way that can be compared to the current government budget. Thus, a simple estimate of the annual subsidy can be calculated as:

$$
\text { Annual subsidy }=S^{T r a d} \cdot \tau_{R} \cdot f \cdot\left(1-\tau_{C}\right) .
$$

The size of the government's implicit account is $S^{\text {Trad }} \cdot \tau_{R}$, where $S^{\text {Trad }}$ is the aggregate amount of tax-deferred retirement savings and $\tau_{R}$ is the effective tax rate on retirement payouts. (Note

\footnotetext{
${ }^{26}$ When selling a security and purchasing another, a fund trades twice; when reinvesting a coupon or principal payment, a fund trades only once. If reported turnover is defined as the lesser of purchases on one hand, and sales plus issuer payments on the other, the " 2 " coefficient would overstate trading costs. In practice, however, many bond funds and indices have rules that cause them to sell bonds before maturity. For instance, "most flagship Bloomberg Barclays Aggregate, High Yield, Inflation-Linked and Emerging Markets Indices have a minimum time to maturity" (Barclays, 2017). In particular, the most widely followed bond index (the Barclays Capital U.S. Aggregate Index) has annual turnover is $42.0 \%$, of which only about one-fifth is due to coupon and principal paydowns (Tucker, 2011). Accordingly, our adjusted coefficient counts one-fifth of the volume once instead of twice $(2 \times 4 / 5+1 \times 1 / 5=1.8)$. To the extent that any funds already report turnover net of issuer payments, our adjustment is conservative. In principle, a similar adjustment should apply to stocks as well, but it would be minimal because of the lack of principal paydowns and an average dividend yield of less than $2 \%$.
} 


\begin{tabular}{lrrr}
\hline \$ billion & Total & \multicolumn{1}{c}{$\begin{array}{c}\text { Roth } \\
\text { (TEE) }\end{array}$} & $\begin{array}{c}\text { Traditional } \\
\text { (EET) }\end{array}$ \\
\hline Total retirement assets & 28,081 & 1,139 & 24,754 \\
Individual retirement accounts (IRAs) & 9,715 & 874 & 8,841 \\
Defined contribution (DC) plans & 8,400 & 264 & 8,136 \\
401(k) and 403(b) & 6,899 & 217 & 6,682 \\
Other private-sector DC & 545 & 0 & 545 \\
Thrift Savings Plan (TSP) & 617 & 10 & 607 \\
457 & 339 & 11 & 328 \\
Annuities & 2,188 & N/A & N/A \\
Defined benefit (DB) plans & 7,778 & 0 & 7,778 \\
\hline
\end{tabular}

Table 5: U.S. Retirement assets by type of account. Source: ICI Retirement Market Statistics 2019q2 (totals and Roth IRAs) and own estimates (Roth DC plans). 401(k), 403(b), and TSP are standard DC plans sponsored respectively by private-sector employers, non-profit employers, and the federal government. Other private-sector DC plans include Keogh, profit-sharing, thriftsavings, stock bonus, and money purchase plans. 457 plans are tax-advantaged deferred compensation arrangements available for certain employers in the United States. DB Plans exclude \$1,679 billion of U.S. government employee DB plans which are required by law to be invested in U.S. government obligations.

that in a two-period setting, such as the one described in Section 2 and the one we will use in Section 5, the flow of individual saving and the stock of accumulated assets are the same and both are denoted by $S$. For this calibration, $S$ corresponds to the stock.) This implicit account incurs investment fees (explicit fees plus trading costs) at an annual average percentage rate $f$. We assume that the government recovers a fraction $\tau_{C}$ of these fees via corporate taxation of the profits of asset managers and other intermediaries.

Next, we calibrate equation (3) on U.S. data. In Section 4 of the Internet Appendix we do the same for six additional countries with the largest dollar size of Traditional retirement assets.

\subsection{Tax-deferred retirement assets in the U.S. $\left(S^{T r a d}\right)$}

Table 5 summarizes the composition of tax-advantaged retirement assets in the U.S. Total retirement assets amount to $\$ 28.1$ trillion. We estimate $S^{\text {Trad }}$ as the total amount of tax-deferred assets in IRAs 
and DC plans. To be conservative, we exclude DB plans (\$7.8 trillion), which are also tax-deferred and to which a similar argument applies. We also exclude annuities (\$2.2 trillion) because their special tax treatment entails only a small amount of tax deferral. The remainder of retirement assets (\$18.1 trillion) includes two main components: employer-sponsored defined contribution retirement accounts such as 401(k) and 403(b) plans (DC plans), and individual retirement accounts (IRAs), with $\$ 8.4$ and $\$ 9.7$ trillion of assets respectively. From these assets we further remove $\$ 0.6$ trillion of assets in the federal government's Thrift Savings Plan (TSP), whose fees are negligible, and \$1.1 trillion of Roth assets. ${ }^{27}$ This results in an estimated amount $S^{\text {Trad }}$ of $\$ 16.4$ trillion.

\subsection{Tax rates $\left(\tau_{R}\right.$ and $\left.\tau_{C}\right)$}

Because of progressive taxation, the effective tax rate on retirement payouts, $\tau_{R}$, is challenging to estimate: it is neither the marginal tax rate on retirement income nor the average, because individuals may have retirement income from sources other than tax-deferred accounts. Rather, the appropriate definition of $\tau_{R}$ is the present value of future taxes that will be paid on all Traditional balances accumulated as of today $\left(S^{\operatorname{Trad}}\right)$, minus the present value of future taxes that would be paid if Traditional distributions were not taxable, as a fraction of the present value of all taxable distributions.

We estimate $\tau_{R}$ using data on retirement wealth reported in the 2013 Survey of Consumer Finances (SCF) and the U.S. marginal tax schedule in place at the time of the survey, assuming they remain constant moving forward from 2013. Our resulting estimate of the effective tax rate on retirement wealth is $25.8 \%{ }^{28}$ This estimate could be overstated because it is obtained assuming

\footnotetext{
${ }^{27}$ The ICI's 2019q2 Retirement Market Statistics report that $\$ 874$ billion of IRA assets is in Roth IRAs. For DC plans, we roughly estimate total Roth assets in $2019 \mathrm{q} 2$ to be $\$ 259$ billion (or 3.6\% of total DC assets) based on information on Roth adoption rates in T. Rowe Price's 2017 Reference Point and Vanguard's How America Saves 2017 reports, together with ICI information on contribution flows, and the fact that Roth options were introduced in 2001 for 401(k) and 403(b) plans. We are not aware of data on Roth options for other private-sector DC plans.

${ }^{28}$ For each SCF observation in which the head of household is aged 65 to 74 we calculate taxable wealth $\left(W^{T}\right)$, and tax-deferred retirement wealth $\left(W^{\text {Trad }}\right)$. We assume baseline retirement taxable income to be equal to taxable wealth times a constant nominal rate of return $r=3 \%\left(Y_{\text {Baseline }}=W^{T} \cdot r\right)$. In addition to this baseline income, we assume that the individual uses $W^{\text {Trad }}$ to withdraw an equal nominal amount each year for 20 years (computed as a term annuity stream using the same rate $r=3 \%$. This implies that $Y_{\text {Combined }}=W^{T} r+W^{\text {Trad }} /\left\{\left[1-(1+r)^{-T}\right] / r\right\}$. Using the 2013 tax schedule, we then calculate total dollar tax on the baseline income $\left(T_{\text {Baseline }}\right)$ and on the combined to-
} 
individuals do not adjust the timing of their withdrawals to take advantage of fluctuating marginal tax rates, but it could also be understated because it does not take into account the taxable part of Social Security benefits and any labor income. As a check, we also reverse-engineer present-value tax expenditure estimates published by the federal government (Office of Management and Budget, 2014) or its staff (Lurie and Ramnath, 2011). Depending on the study, we obtain a range for the effective marginal tax rate of $20 \%-30 \%$. As a conservative estimate we use $20 \%$, the lowest of all our estimates. Note that this estimate also excludes any state income taxes on Traditional retirement payouts. The size of the implicit government account is therefore $S^{T r a d} \cdot \tau_{R}=3.3$ trillion.

For $\tau_{C}$, the corporate tax rate, we simply use the top statutory corporate tax rate of $21 \%$.

\subsection{Calibration}

Using the calibrated inputs in equation (3), we obtain our estimate:

$$
\begin{gathered}
\text { Annual subsidy }=S^{\text {Trad }} \cdot \tau_{R} \cdot f \cdot\left(1-\tau_{C}\right)= \\
=\$ 16.4 \times 20 \% \times 0.80 \% \times(1-21 \%)=\$ 20.7 \text { billion. }
\end{gathered}
$$

This amount is equal to $5.7 \%$ of the size of the total interest paid on the federal debt ( $\$ 364$ billion) or $2.1 \%$ of the federal budget deficit ( $\$ 964$ billion), and is about the size of the 2019 budget of NASA ( $\$ 21.5$ billion). ${ }^{29}$ This amount is also equal, clearly, to a fraction $\tau_{R}\left(1-\tau_{C}\right) \approx 16 \%$ of the asset management industry's total fee revenue from tax-deferred DC plans and IRAs.

As discussed above in Section 4.1, our estimate of assets under management excludes \$7.8 trillion of tax-deferred assets in state and local government and corporate defined-benefit pension plans. Although these assets do not belong to any individual in particular, they are subject to the same tax deferral benefit: the contribution is made with pretax money, and benefits are taxed only when paid out. Therefore, defined-benefit plan assets can also be decomposed into an employees' account and a government account earmarked to pay future taxes. While defined-benefit plans are

tal income $\left(T_{\text {Combined }}\right)$, and calculate $\tau_{R}$ as $\left[\sum_{i}\left(T_{\text {Combined }, i}-T_{\text {Baseline }, i}\right) w_{i}\right] /\left[\sum_{i}\left(Y_{\text {Combined }, i}-Y_{\text {Baseline }, i}\right) w_{i}\right]$, where $w_{i}$ are the SCF sampling weights for household $i$.

${ }^{29}$ See https://spacenews.com/final-fiscal-year-2019-budget-bill-secures-21-5-billion-for -nasa/ and Budget of the U.S. Government, FY 2019, available at https://www.govinfo.gov/app/collection /budget/2019. 
likely to be more efficient investment vehicles than defined contribution plans or IRAs, they still incur investment fees. Accounting for the government's implicit share of DB assets would increase our estimate of the government's account by another $\$ 7.8 \times 20 \%=\$ 1.6$ trillion. Assuming lower fees for DB plans ( 45 bps instead of $80 \mathrm{bps}$ ), ${ }^{30}$ the estimated subsidy rises to $\$ 26.2$ billion.

\subsection{Does the government receive value for the fees it pays?}

In the calibration above, we have ignored any potential benefits the government obtains in exchange for the fees paid on its virtual account, including both direct benefits (portfolio services, alpha), and indirect macroeconomic benefits. We argue that the former and parts of the latter are likely to be small, and we explicitly model the remainder of the latter in our general equilibrium model in Section 5 .

\subsubsection{Direct benefits}

A substantial fraction of the fees on mutual funds and other structured products held in retirement accounts covers recordkeeping, distribution, and marketing. ${ }^{31}$ The implicit government account, however, does not benefit from these services. Another fraction of fees covers valuable advice on asset allocation and the creation of products to implement such an allocation, such as funds focusing on style (conservative/aggressive) or personal situations (target-date funds). These benefits largely cancel out in aggregate for the government, which holds a fraction of all individual accounts. Moreover, if the advice results in lower fees, this benefit is already reflected in the observed level of fees. To the extent that the fees paid by the government on its implicit account result in cheaper

\footnotetext{
${ }^{30}$ This rough estimate is implied by Table II of Dyck and Pomorski (2011). We define total plan fees as "Overall asset-class-level costs" plus "Plan-level administrative costs" and calculate an approximate asset-weighted average of 31 bps based on the average plan size in each of the size quintiles. To this figure we add our estimate of trading costs of $14 \mathrm{bps}$.

${ }^{31}$ While we do not have data on cost breakdowns within retirement accounts, data on the general asset management sector support this view. Roussanov et al. (2018) find that distribution fees are close to one-third of revenue. As an example, we examined the 2017 annual report of Invesco, one of the largest listed U.S. investment management companies. Invesco had operating revenues of $57 \mathrm{bps}$, with third-party distribution, service and advisory expenses (including passing through of $12 \mathrm{~b}-1$ and similar fees) of $17 \mathrm{bps}$, and direct marketing expenses of $1.4 \mathrm{bps}$, totaling $32 \%$ of revenue.
} 
or better services for individuals, we examine this possibility explicitly in the next section.

The government does benefit from basic portfolio management services on its implicit account, but these services are an inexpensive commodity. For instance, the U.S. federal government's Thrift Savings Plan (TSP) pays BlackRock no explicit portfolio management fees for its stock funds, all of which are index funds, instead only giving up roughly 1 bps worth of securities lending revenue (Thrift Savings Plan, 2018). Thus, if the government wanted to obtain exposure to stocks or any other securities, it could invest directly in a passive vehicle at very low cost. Such a vehicle would not provide those services that the government does not need, but is currently paying for, in Traditional accounts.

Finally, the government may benefit from abnormal return, or "alpha." If funds that charge higher fees also have higher risk-adjusted expected returns (as in Berk and Green, 2004), active management pays for itself, and therefore the net cost of asset management for both investors and the government is much less than the observable fees. ${ }^{32}$ For our purposes, however, alpha must represent real value that funds in aggregate create and capture by trading. Active funds held in tax-deferred accounts must either be systematically winning a zero-sum game against other market participants, or they must be making prices more efficient and capturing the resulting value (e.g., in the same way as activist hedge funds). The existing empirical evidence paints a pessimistic picture: in aggregate, mutual funds lose the zero sum game against other market participants (Shive and Yun, 2013; Ince et al., 2018, etc.) and aggregate alpha is negative (Fama and French, 2010; Berk and van Binsbergen, 2015). ${ }^{33}$ Furthermore, even if aggregate alpha were positive, an increase in assets due to a switch from Roth to Traditional would likely result in lower abnormal returns because of industry-level diminishing returns to scale in asset management (Pástor and Stambaugh, 2012; Pástor et al., 2015).

\footnotetext{
${ }^{32}$ Roussanov et al. (2018) show that adding marketing and search costs to a model like Berk and Green (2004) has the potential to explain the distribution of fund size. In their model, active management does not pay for itself.

${ }^{33}$ Berk and van Binsbergen (2015) compare active funds against "investable" benchmarks (i.e., retail shares of Vanguard funds), estimating a value-weighted net alpha of $-12 \mathrm{bps}$. This cost of active management is in addition to the cost of investing in the specific passive benchmark (18 bps plus any implicit trading costs). According to Petajisto (2009), the S\&P 500 index itself has implicit trading costs of 20-28 bps. Adding account-level fees would imply total investment fees of the same order of magnitude as ours, though somewhat lower.
} 


\subsubsection{Indirect macroeconomic benefits}

The existence of an implicit government account and the associated subsidy entail a few possible indirect macroeconomic benefits. First, roughly two-thirds, or \$2 trillion, of the U.S. government's implicit portfolio under Traditional is invested in equities, thus giving the government substantial exposure to the higher risk and higher expected return of the stock market. We have discussed the potential value of government ownership of stock in Section 2.5, and argued that the added government exposure under Traditional would be beneficial only if the government desires it and cannot obtain it in a less expensive way.

Second, active asset managers may create a positive externality if they make prices more efficient and do not fully capture through trading the value they generate (Grossman and Stiglitz, 1980). It remains an open question, however, whether the proportional scaling up in demand for active management from a hypothetical switch from Roth to Traditional would actually aid price discovery and improve the efficiency of capital markets, as this may depend on whether firms simply scale up each trade or put more resources into actively choosing trades. Moreover, since a substantial fraction of tax-deferred assets are managed passively, Traditional accounts may only work as a blunt tool to subsidize price discovery because the extra assets benefit active and passive managers indiscriminately. ${ }^{34}$

Third, issuing government debt and transferring the proceeds to private agents who would otherwise borrow (or want to borrow) through private markets has been shown in some contexts to lower the costs of intermediation and be efficient (Barro, 1974; Aiyagari and McGrattan, 1998; Heathcote, 2005). In our context, however, rather than reducing private borrowing, the transfer and associated debt issuance instead increase private sector saving in retail retirement accounts. Thus, the transfer is inefficient because it generates substantial investment costs and thereby adds to intermediation costs. ${ }^{35}$

Finally, consumers may receive benefits from better or cheaper services that could arise as a

\footnotetext{
${ }^{34}$ Moreover, retail investment funds are unlikely to be effective at price discovery (Gârleanu and Pedersen, 2018).

${ }^{35}$ Another source of the government's comparative advantage in borrowing is private agents' demand for safe and liquid assets (Holmström and Tirole, 1998; Krishnamurthy and Vissing-Jorgensen, 2012). However, tax deferral creates both supply (new government borrowing) and demand (new private wealth).
} 
result of the expansion of the number of asset management firms. We address this possibility in the general equilibrium model in the next section, where we explicitly incorporate the benefits of additional asset management firms.

\section{A general equilibrium model of retirement savings and asset management}

In this section, we build and solve a simple, two-sector general equilibrium model to address four questions. First, are the aggregate resources devoted to asset management higher under Traditional than under Roth? Second, who bears the incidence of these higher costs? Third, how do fees charged vary across systems? And fourth, which system (Roth or Traditional) results in higher social welfare? Our model includes an asset management industry with fixed and variable costs, allows for firm entry and exit, and is compatible with the basic empirical evidence about cost structure, market structure, and competition in the asset management industry. If all asset management costs were variable and proportional to assets under management, our partial equilibrium results on the extra aggregate resources devoted to asset management under Traditional would carry through to general equilibrium. To stress-test this result, we allow for the possibilities that: (i) some or all asset management costs at the firm level are fixed, consistent with evidence suggesting economies to scale as firms expand AUM, and (ii) that new asset management firms generate some value to consumers. Nevertheless, we find that Traditional in the model involves higher resources devoted to asset management and lower social welfare than Roth.

\subsection{Modeling choices}

We begin by describing the nature of the choices we make in constructing the general equilibrium model, including cost structure, market structure and competition, and firm entry. 


\subsubsection{Cost structure}

A key modeling choice relates to the existence and magnitude of economies of scale in the asset management industry. The academic literature has considered two related but distinct sources of economies of scale in asset management: costs and performance.

On the cost side, the existence of economies of scale with assets under management seems uncontroversial: most empirical studies agree that larger funds and larger plans have lower administrative costs per dollar of AUM. ${ }^{36}$ Statements by industry insiders also support this idea: Kahn (2002) quotes the director for portfolio review at a major fund family as saying that the "marginal cost of managing increasing dollars is minimal." To represent these economies of scale, we use a simple, firm-level cost function equal to the sum of a fixed component and a variable component that is proportional to assets under management.

On the performance side, the picture is more nuanced. On one hand, Dyck and Pomorski (2011) show that larger DB plans outperform smaller ones at least in part because of access to a better investment opportunity set. On the other hand, as discussed in Section 4.4.1, for active mutual funds the existence of diseconomies of scale has been theorized and empirically demonstrated both at the fund level and the industry level. ${ }^{37}$ We do not directly model investment performance and therefore net economies of scale are positive in our model.

\subsubsection{Market structure and competition}

There is abundant evidence that investors are not very sensitive to the price of asset management services. Hortacsu and Syverson (2004) note that in 2000 there existed 82 S\&P 500 index fund share classes (50 distinct funds) with large dispersion in fees (an interquartile range of $98 \mathrm{bps}$ ). We update their analysis and find that price dispersion persists: in 2016 there existed 79 share classes

\footnotetext{
${ }^{36}$ Latzko (1999); Gao and Livingston (2008); Hubbard et al. (2010); Dyck and Pomorski (2011).

${ }^{37}$ Diseconomies of scale have been theorized at the fund level (Perold and Salomon, 1991; Berk and Green, 2004; Gabaix et al., 2006) and the industry level (Pástor and Stambaugh, 2012). The available evidence shows that size is negatively associated with performance both at the fund level (Chen et al., 2004; Yan, 2008; Berk and van Binsbergen, 2015) and at the industry level (Pástor et al., 2015).
} 
(46 distinct funds) with a fee interquartile range of 102 bps. $^{38}$ Although funds with lower fees tend to have higher market shares (Hubbard et al., 2010), multiple studies point to the existence of dominated products. ${ }^{39}$

To capture limited price sensitivity, we build a model of monopolistic competition with differentiated products based on Salop (1979). In this model, asset management firms face a downwardsloping demand function, i.e. if they raise their fees, their demand falls, but not to zero. Our approach is conservative in that every additional firm entering the market creates value for some investors, i.e. there are no dominated funds. Alternative choices such as informational or behavioral frictions would have likely generated stronger welfare losses in the model under Traditional relative to Roth. ${ }^{40}$

Another important feature of asset management markets is the existence of tiered pricing (decreasing marginal fees) based on account size, which results in decreasing average fees as a function of account size. To approximately capture this feature, we assume firms set a two-part fee structure with a fixed component and a variable component proportional to assets.

\subsubsection{Entry}

Empirical evidence and casual observation suggest low barriers to entry in the mutual fund industry (Hubbard et al., 2010). In 2018 alone, 345 new mutual funds, 237 new exchange-traded funds, and

\footnotetext{
${ }^{38}$ Christoffersen and Musto (2002) show evidence of fee dispersion for money market mutual funds. Cooper et al. (2018) show that fee dispersion has increased over the last 20 years in a comprehensive study of equity mutual funds with homogeneous holdings.

${ }^{39}$ E.g., funds that are more costly and underperform (Bergstresser et al., 2009; Gil-Bazo and Ruiz-Verdú, 2009), structured equity products with negative expected returns (Henderson and Pearson, 2011), and "closet indexers" that charge fees as if they are active (Cremers et al., 2016).

${ }^{40}$ All proposed explanations for price insensitivity point to information frictions or outright inertia: marketing (Roussanov et al., 2018), search costs (Hortacsu and Syverson, 2004), captive DC plan participants (Pool et al., 2016), shrouded prices (Gabaix and Laibson, 2006; Carlin, 2009), noisy quality of fund management (Gil-Bazo and RuizVerdú, 2008; Gârleanu and Pedersen, 2018), relationships or trust (Bergstresser et al., 2009; Hubbard et al., 2010; Gennaioli et al., 2015), or even irrationality (Elton et al., 2004). To reflect this evidence, we could have based our analysis on a search-based model like Anderson and Renault (1999) or Roussanov et al. (2018), which would generally result in high prices and either excessive entry or excessive marketing expenditure. Other alternatives include a model with captive demand and shrouded fees or one based on trust such as Gennaioli et al. (2015).
} 
40 new fund sponsors entered the industry (ICI, 2019). ${ }^{41}$ To reflect this evidence, we assume that there is no entry cost (other than the fixed operating cost), and we allow firms to enter the market until profits are zero. Because our model allows for product differentiation, the assumption of a dominant fixed cost component does not result in a monopoly.

\subsection{Demand: individuals}

Our model is based on Salop's (1979) circular city, which we embed in a two-period economy. There is a unit continuum of individuals $i \in[0,1)$ uniformly distributed over a circle of circumference 1 (Figure 3). When individuals are young $(t=0)$, they work, consume, and save for retirement. When old $(t=1)$, individuals retire and consume all of their accumulated savings (net of any taxes), leaving no bequest.

Young individuals are endowed with one unit of labor, which they supply inelastically. Individuals can work either in the consumption goods sector or in the asset management sector, and are indifferent (at the same wage) between the two. The production technology is linear, i.e., the marginal (and average) product of labor is $\omega$. Since labor markets are frictionless, $\omega$ also equals the wage of each worker.

Asset management services in our model are a differentiated product. Individual savings, $S_{i}$, must be allocated to one of $N$ firms, indexed by $j \in\{1,2, \ldots N\}$. Firms are situated on the circle at locations $\iota_{1}, \iota_{2}, \ldots \iota_{N}$. Each individual's utility depends negatively on the "distance" from their chosen firm. A low distance can be thought of as literally low physical distance from the nearest branch, but also ease of finding, trust, a preference for portfolio characteristics of firms, or even non-portfolio characteristics such as the level of customer service. Unlike asset management services, the market for consumption goods is perfectly competitive. ${ }^{42}$

\footnotetext{
${ }^{41} \mathrm{~A}$ similar situation is reflected in the non-mutual fund segments of the asset management industry. For instance, the majority of the leading third-party retirement plan administrators were established in the past 25 years (see Plansponsor's 2016 TPA survey of 1,070 administrators available at http://www.plansponsor.com/2016-T hird-Party-Administrator-Survey/).

${ }^{42}$ This assumption is not relevant to our later results because a switch from Roth to Traditional does not create any artificial demand for consumption goods - only for asset management.
} 


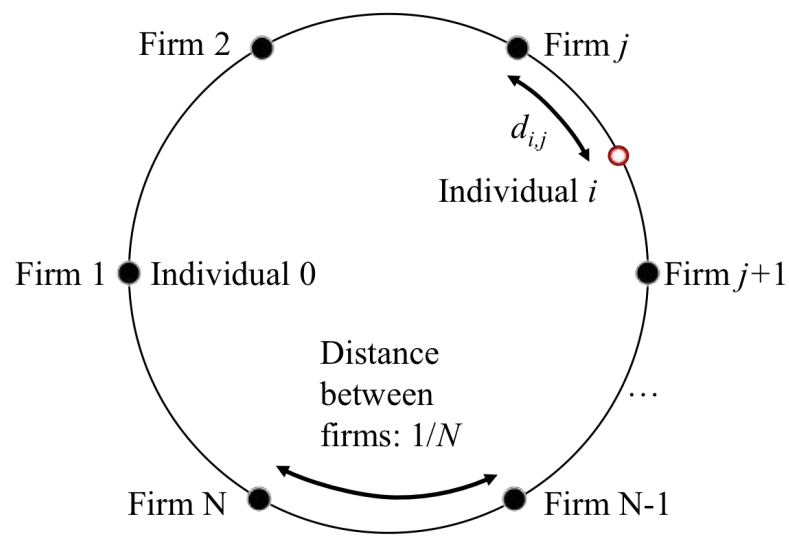

Figure 3: Spatial competition. $N$ firms are uniformly spaced along a circle of circumference 1, as in Salop (1979). Individuals are distributed uniformly along the circle, and prefer firms located at a closer distance.

We assume that the utility of individual $i$ is

$$
u_{i}\left(C_{0, i}, C_{1, i}, d_{i, j}\right)=\ln C_{0, i}+\delta \ln C_{1, i}-\gamma \ln d_{i, j} .
$$

Individuals derive utility from current real consumption $\left(C_{0, i}\right)$ and future real consumption $\left(C_{1, i}\right)$ discounted by a factor $\delta$, and derive disutility from the (shortest) distance between their own location $i$ and the location $\iota_{j}$ of their chosen firm $j, d_{i, j} \equiv\left|i-\iota_{j}\right|$. We choose this logarithmic utility specification because it is both economically sensible and tractable, yielding easy-to-interpret expressions for the quantities of interest. ${ }^{43}$

\footnotetext{
${ }^{43}$ We are not aware of any works using the circular city model that feature either an intertemporal choice problem or logarithmic distance disutility. Salop (1979) and many subsequent works feature linear consumption utility and linear or quadratic distance disutility (see Gong et al., 2016, for a review). We choose logarithmic consumption utility because linear consumption utility does not permit us to study the savings decision. We choose logarithmic distance disutility for tractability, and because it allows for an interpretation of "distance" as something whose importance increases with the individual's wealth.

One potential problem with logarithmic distance disutility is that individuals living at exactly zero distance from their firm have infinite utility. This is not technically problematic. The planner's problem is well-defined because the integral of $u(\cdot)$ over the $[0,1)$ circle is finite, and the market equilibrium is unaffected by these individuals because their utility can still be maximized with respect to $C_{0}$ and $C_{1}$, and firms do not find it profitable to charge infinite (or $100 \%$ ) fees. However, if one were to find this setup philosophically problematic, the same results could be obtained by assuming that no individuals live in an $\varepsilon$-neighborhood centered around each firm and examining the limit as $\varepsilon \rightarrow 0$.
} 


\subsection{Supply: Firms}

The unit of production is a generalist firm that produces asset management services. We ignore the existence of multiple layers of financial intermediation (e.g., recordkeepers, asset managers, fund families, subadvisors, securities brokers, etc.). We assume a linear storage technology with exogenous non-stochastic real return $r$, and allow storage to be positive or negative. Each firm invests its assets in this storage technology or in riskless government bonds (which, by no-arbitrage, yield $r$ as well) and incurs costs described below. Following Salop (1979), we assume the $N$ firms are evenly distributed around the circle, as shown in Figure 3, and that $N$ can be noninteger. ${ }^{44}$

We assume that all costs (measured in goods) are incurred by firm $j$ at time 0 , and equal

$$
\operatorname{Cost}_{j}=\phi+c \cdot A U M_{j},
$$

where $\phi$ is the fixed component, and $c \cdot A U M_{j}$ is the variable component, equal to a fraction $c$ of assets under management of firm $j{ }^{45}$ Since the marginal product of labor is $\omega$, and defining $A U M \equiv \sum_{j=0}^{N} A U M_{j}$, the amount of labor going to the asset management sector is

$$
L \equiv \frac{N \cdot \phi+c \cdot A U M}{\omega},
$$

and the amount of labor going to the consumption goods sector is $1-L$.

\subsection{The planner's problem}

We characterize the social optimum in the model by assuming the planner directly chooses individual consumption $\left\{C_{0, i}\right\}$ and $\left\{C_{1, i}\right\}$ and the number of firms $N$ to maximize the sum of individual

\footnotetext{
${ }^{44}$ These assumptions lighten the exposition considerably and are consistent with the existing literature. It is easy to show that equidistant firms maximize social welfare and a planner would choose this location pattern. Economides (1989) derives location endogenously in a three-stage game, albeit at the cost of restrictions on the utility function and greater complexity. Requiring $N$ to be integer can lead to a situation in which $N$ firms make positive profits, and $N+1$ firms make negative profits. This possibility, which could have important consequences if $N$ were small, is analyzed by Mankiw and Whinston (1986).

${ }^{45}$ Note that under this specification firms incur variable costs on their gross AUM, i.e., including the part that is used to cover fixed costs. Therefore, the fixed cost of operating a firm in the usual sense is $\phi /(1-c)$, not $\phi$. This assumption is made for tractability and does not affect our results qualitatively.
} 
utilities:

$$
\begin{gathered}
\max _{\left\{C_{0, i}\right\},\left\{C_{1, i}\right\}, N} U \\
U \equiv \int_{0}^{1}\left(\ln C_{0, i}+\delta \ln C_{1, i}-\gamma \ln d_{i, j}\right) d i
\end{gathered}
$$

subject to the resource constraint

$$
C_{1}=\left[\left(\omega-C_{0}-G\right)(1-c)-\phi N\right](1+r),
$$

where $C_{t} \equiv \int_{0}^{1} C_{t, i} d i$ is aggregate consumption at time $t \in\{0,1\}, G$ is an exogenously given amount of public expenditure, and $r$ is the exogenously given return on the storage technology. Since we assume that no production occurs in period 1, the only way the planner can allocate consumption in period 1 is via the asset management industry. The planner incurs variable asset management costs at rate $c$ on $\omega-C_{0}-G^{46}$

The planner optimally allocates equal consumption to all individuals $\left(C_{0, i}=C_{0}\right.$ and $\left.C_{1, i}=C_{1}\right)$, because consumers have identical preferences and productivity and because the planner's objective function is concave, separable in its arguments (consumption and distance), and unaffected by inequality in utility caused by, e.g., differences in distance. Since all firms are identical except for location, it is also optimal for the planner to allocate each consumer to the nearest firm. Using the assumption that the $N$ firms are located equidistantly along the circle, the planner's objective function simplifies (see Section 1 of the Internet Appendix for a derivation) to

$$
\begin{gathered}
\max _{C_{0}, C_{1}, N} U, \\
U=\ln C_{0}+\delta \ln C_{1}+\gamma \ln N-\gamma(1+\ln 2) .
\end{gathered}
$$

There are two first-order conditions. The first is

$$
U^{\prime}\left(C_{0}^{*}\right)=\delta(1+r)(1-c) U^{\prime}\left(C_{1}^{*}\right)
$$

where $U^{\prime}\left(C_{t}\right) \equiv \partial U / \partial C_{t}=1 / C_{t}$. This equation says that, at the planner's optimum, the marginal cost in terms of lost utility of giving the consumer one less dollar of period-0 consumption must

\footnotetext{
${ }^{46}$ Consistent with the cost function in equation (6), the planner incurs variable costs on all of $\omega-C_{0}-G$, including the resources devoted to the fixed costs of asset management.
} 
equal the marginal benefit of allocating that dollar plus returns and net of the marginal asset management costs to period 1 consumption.

The second first-order condition, related to the choice of $N$, is

$$
\phi \frac{1}{1-c} U^{\prime}\left(C_{0}^{*}\right)=\frac{\gamma}{N^{*}},
$$

and says that at the optimum the cost of adding another firm, $\phi /(1-c)$, expressed in units of utility, must equal the utility benefit, $\gamma / N$, that arises due to the drop in the average distance.

Combining and simplifying the first-order conditions yields the following optimal quantities:

$$
\begin{aligned}
C_{0}^{*} & =\frac{1}{1+\delta+\gamma}(\omega-G), \\
C_{1}^{*} & =\frac{\delta}{1+\delta+\gamma}(\omega-G)(1-c)(1+r), \\
N^{*} & =\frac{\gamma}{1+\delta+\gamma}(\omega-G)(1-c) \frac{1}{\phi} .
\end{aligned}
$$

Note that the distaste for distance enters into the formulae for optimal consumption in each period, because it affects the optimal number of firms, and thus the aggregate resources available for consumption. Note also that $N^{*} \phi$, the total allocation to the fixed costs of asset management, does not depend on the size of the fixed cost $\phi$.

\subsection{The market economy}

In the market equilibrium, individuals pay taxes, choose consumption $\left(C_{0, i}\right.$ and $\left.C_{1, i}\right)$ and private saving $\left(S_{i}\right)$, and allocate their savings to a firm $(j)$ to maximize utility. Again note that since this is a two-period non-overlapping generations model, the flow of private saving equals the stock of accumulated assets and we use the same notation for each. The $N$ firms set their fees to maximize profits $\pi_{j}$, taking competitors' choices as given. We assume that firms cannot engage in price discrimination based on distance, and that each firm $j$ charges each of its customers a two-part fee structure: a fixed component $F_{j}$ and a variable component $f_{j}^{v}$ per dollar of saving. 


\subsubsection{Government spending and taxes}

At time 0 , the government spends an exogenously given amount $G$, taxes individuals' labor income at a rate $\tau_{L}$, and grants individual $i$ an income tax deduction of $\tau_{S}$ for each dollar contributed to retirement saving $\left(S_{i}\right)$. At time 1 , the government taxes retirement income at a rate $\tau_{R}$. The values of $\tau_{S}$ and $\tau_{R}$ depend on the specific incentive system (Roth or Traditional). Under Roth, the government grants no deduction $\left(\tau_{S}^{\text {Roth }}=0\right)$ and does not tax retirement income $\left(\tau_{R}^{\text {Roth }}=0\right)$. Under Traditional, the government grants a deduction for saving at the same rate as labor income $\left(\tau_{S}^{T r a d}=\tau_{L}\right)$. For simplicity, we assume that aggregate firm profits $\Pi=\sum_{j=1}^{N} \pi_{j}$ are rebated at time 0 to consumers (an equal amount per consumer) and are taxed at the personal level only, at the same rate as labor income.

\subsubsection{The individual's problem}

At time 0, individuals earn labor income $\omega$ and receive profits $\Pi$. Each individual pays taxes $T_{0, i}$, consumes $C_{0, i}$, and saves and invests the remainder $S_{i}=\omega+\Pi-T_{0, i}-C_{0, i}$ to finance retirement consumption $C_{1, i}$. Since $T_{0, i} \equiv \tau_{L}(\omega+\Pi)-\tau_{S} S_{i}$, the following budget constraints hold:

$$
\begin{gathered}
C_{0, i}+S_{i}=(\omega+\Pi)\left(1-\tau_{L}\right)+\tau_{S} S_{i}, \\
C_{1, i}=\left[S_{i}\left(1-f_{j}^{v}\right)-F_{j}\right](1+r)\left(1-\tau_{R}\right) .
\end{gathered}
$$

Note that (18) can be rewritten as

$$
S_{i}=\frac{(\omega+\Pi)\left(1-\tau_{L}\right)-C_{0, i}}{1-\tau_{S}} .
$$

We assume for simplicity that any legal limits on the amount of saving that individuals can put into either type of retirement account, if present, are large enough that they are never binding. We also assume that the individual must allocate all saving to one firm, $j$. Moreover, to rule out what Salop (1979) calls a "supercompetitive" equilibrium (the situation in which a firm charges sufficiently low fees to be competitive with firms other than its immediate neighbors), we assume 
that the individual only considers the two nearest firms (denoted $j^{-}$and $\left.j^{+}\right){ }^{47}$ Thus, the individual chooses $C_{0, i}$ and $j$ to maximize utility $u_{i}$ :

$$
\max _{C_{0, i}, j} \ln C_{0, i}+\delta \ln C_{1, i}-\gamma \ln d_{i, j},
$$

subject to the budget constraints (18) and (19). The individual's first-order condition with respect to consumption is

$$
u_{i}^{\prime}\left(C_{0, i}\right)=\delta(1+r)\left(1-f_{j}^{v}\right)\left(1+\tau_{M}\right) u_{i}^{\prime}\left(C_{1, i}\right)
$$

where $u_{i}^{\prime}\left(C_{t, i}\right) \equiv \partial u_{i} / \partial C_{t, i}=1 / C_{t, i}$, and $\tau_{M}$ is the government implicit "match" rate, equal to $\left(\tau_{S}-\tau_{R}\right) /\left(1-\tau_{S}\right)$. This equals $\left(\tau_{L}-\tau_{R}\right) /\left(1-\tau_{L}\right)$ under Traditional, because of the difference in working and retirement tax rates, and zero under Roth. ${ }^{48}$ This first-order condition differs from that of the planner in two ways. First, a non-zero match changes the tilt in the consumption path $\left(C_{1, i} / C_{0, i}\right)$, with a positive match increasing and a negative match decreasing the tilt. ${ }^{49}$ Second, for the planner the cost of future consumption relative to today's consumption depends only on the return on assets net of variable costs $[(1+r)(1-c)]$, whereas for the individual it depends on the return on assets net of variable fees $\left[(1+r)\left(1-f_{j}^{v}\right)\right]$.

For the choice of a firm there is no first-order condition. Individuals simply pick the one out of two nearest firms that gives them the highest utility:

$$
j^{*}=\arg \max _{j \in\left\{j^{-}, j^{+}\right\}} \ln C_{0, i}+\delta \ln C_{1, i}-\gamma \ln d_{i, j},
$$

where both $C_{0, i}$ and $C_{1, i}$ are functions of $j$. In choosing a firm, individuals are willing to pay higher fees (and thus have lower consumption) for the convenience of lower distance $d_{i, j}$.

\footnotetext{
${ }^{47}$ Assuming individual $i$ is at clockwise distance $i$ from firm $1, j^{-} \equiv(\lfloor i N\rfloor \bmod N)+1$, and $j^{+} \equiv$ $(\lfloor i N+1\rfloor \bmod N)+1$, with $i \in[0,1)$ and $j \in\{1,2, \ldots N\}$.

${ }^{48}$ Each dollar of initial-period consumption that is given up generates an extra $1 /\left(1-\tau_{S}\right)$ dollars of saving. As described in Section 2.2 above, each dollar of Traditional saving is effectively matched by a government contribution equal to $\tau_{L}-\tau_{R}$.

${ }^{49}$ Note that, in our setup, labor income taxes do not distort labor supply (which is fixed), whereas capital income taxes introduce a wedge in the Euler equation and discourage saving.
} 


\subsubsection{Competition between firms and the firm's problem}

Each of the $N$ firms chooses $f_{j}^{v}$, its variable fee, and $F_{j}$, its fixed fee, to maximize profits $\pi_{j}$. The firm understands that its fee choices affect both its market share, $q_{j}$, and the saving choices of each of its investors, which we denote as $S_{j},{ }^{50}$ but it takes aggregate profits and competitors' choices as given. The firm maximizes profit $\pi_{j}$, calculated as fee revenue, $\left(F_{j}+f_{j}^{v} S_{j}\right) q_{j}$, minus variable costs, $c S_{j} q_{j}$, minus the fixed cost $\phi$ :

$$
\max _{f_{j}^{v}, F_{j}}\left[F_{j}+\left(f_{j}^{v}-c\right) S_{j}\right] q_{j}-\phi
$$

where $f_{j}^{v}-c$ is the markup of variable fees over marginal cost. The firm has first-order conditions

$$
\begin{gathered}
\frac{\partial \pi_{j}}{\partial f_{j}^{v}}=S_{j} \cdot q_{j}+\left[F_{j}+\left(f_{j}^{v}-c\right) S_{j}\right] \cdot \frac{\partial q_{j}}{\partial f_{j}^{v}}+\left(f_{j}^{v}-c\right) \cdot \frac{\partial S_{j}}{\partial f_{j}^{v}} \cdot q_{j}=0, \\
\frac{\partial \pi_{j}}{\partial F_{j}}=q_{j}+\left[F_{j}+\left(f_{j}^{v}-c\right) S_{j}\right] \cdot \frac{\partial q_{j}}{\partial F_{j}}+\left(f_{j}^{v}-c\right) \cdot \frac{\partial S_{j}}{\partial F_{j}} \cdot q_{j}=0 .
\end{gathered}
$$

Raising variable fees $f_{j}^{v}$ by 1 basis point has three effects. First, the firm gains some revenue on its existing market share $\left(S_{j} \cdot q_{j}\right)$; second, the firm loses some market share $\left(\partial q_{j} / \partial f_{j}^{v}<0\right)$ and the associated margin over variable costs $\left[F_{j}+\left(f_{j}^{v}-c\right) S_{j}\right]$; third, the investors that choose to remain with firm $j$ may change saving $\left(\partial S_{j} / \partial f_{j}^{v}>0\right)$, so that the firm earns the markup over marginal cost on the additional assets. ${ }^{51}$ Raising fixed fees $F_{j}$ by 1 cent has the same three types of effects. Equations (25) and (26) say that the firm's optimal fee level is such that the three effects balance out.

\subsection{Market equilibrium}

Individuals choose the amount of optimal saving, and a firm to manage it, given the firms' fee structures. Firms set their fee structure taking into account the functions determining consumer

\footnotetext{
${ }^{50}$ Conditional on having chosen firm $j$, all of its investors (which are identical in all respects except for their position on the circle) will make the same consumption and saving choices.

${ }^{51}$ This last term is a second-order effect due to the existence of fixed fees. Optimal saving given fees equals $S_{i}=\left[\delta(\omega+\Pi)\left(1-\tau_{L}\right) /\left(1-\tau_{S}\right)+F_{j} /\left(1-f_{j}\right)\right] /(1+\delta)$. If $F_{j}=0$, the second term inside the square brackets disappears and we recover the familiar result under logarithmic utility that upon a change in variable fees $f_{j}^{v}$, income and substitution effects cancel out and saving is unaffected.
} 
saving and firm choice. The market equilibrium described below is a set of values $\left(N, f^{v}, F\right.$, $S_{0, i}, j$ ) such that firms are maximizing their profits, individuals are maximizing their utility, the individual and government budget constraints are satisfied, and markets clear. We start by solving for the equilibrium with $N$ fixed, and then later allow $N$ to be determined by endogenous entry.

\subsubsection{Equilibrium fees, consumption, and saving}

Firms choose both $f_{j}^{v}$ and $F_{j}$. We examine a symmetric equilibrium in which each firm has market share $q_{j}=1 / N$ and therefore total assets under management of $S / N$. Equilibrium fees are

$$
\begin{gathered}
f_{j}^{v}=f^{v}=c \\
F_{j}=F=\frac{2 \gamma}{1+\delta+2 \gamma}(1-c)(\omega+\Pi) \frac{1-\tau_{L}}{1-\tau_{S}} .
\end{gathered}
$$

These results are derived in Section 1 of the Internet Appendix, where we also consider what happens if firms are restricted to set either $f_{j}^{v}$ or $F_{j}$ to zero.

In equilibrium, the variable component of fees is equal to variable costs, i.e. there is no markup over variable costs; firms cover all fixed costs and extract all surplus via the fixed component of fees. This is a well-known result for two-part pricing schedules (see, e.g., Oi, 1971; Tirole, 1988, Ch. 3). When variable fees equal variable costs, investors' demand for asset management services is not distorted and firms have relatively more surplus available to extract. Firms charge fixed fees based on customers' willingness to pay, which depends on lifetime resources and the extent to which fees are effectively deductible from taxes. Because of logarithmic distance disutility, fees depend on the number of firms only via $\Pi$ (directly, and via the tax rates).

Since all individuals have the same values of $C_{0, i}, C_{1, i}$, and $S_{i}$, aggregate values $\left(C_{0} \equiv \int_{0}^{1} C_{0, i} d i\right.$, $\left.C_{1} \equiv \int_{0}^{1} C_{1, i} d i, S \equiv \int_{0}^{1} S_{i} d i\right)$ are equal to the individual values. Solving yields

$$
\begin{aligned}
C_{0} & =\frac{1}{1+\delta+2 \gamma}(\omega+\Pi)\left(1-\tau_{L}\right), \\
C_{1} & =\frac{\delta}{1+\delta+2 \gamma}(\omega+\Pi)\left(1-\tau_{L}\right)(1-c)(1+r)\left(1+\tau_{M}\right), \\
S & =\frac{2 \gamma+\delta}{1+\delta+2 \gamma}(\omega+\Pi) \frac{1-\tau_{L}}{1-\tau_{S}},
\end{aligned}
$$


where $C_{0}, C_{1}, S, \Pi$, and each of the tax rates depend both on the regime (Roth or Traditional) and on the number of firms $N$ (again via $\Pi$ ).

Combining equations (27)-(31) and solving yields equations for aggregate fees, profits, and saving:

$$
\begin{gathered}
F_{j}=F=\frac{\omega-\phi N}{\frac{1+\delta+2 \gamma}{2 \gamma} \cdot \frac{1}{1-c} \cdot \frac{1-\tau_{S}}{1-\tau_{L}}-1}, \\
\Pi=\sum_{j} \pi_{j}=F-\phi N=\frac{\omega-\phi N}{1-\frac{2 \gamma}{1+\delta+2 \gamma}(1-c) \frac{1-\tau_{L}}{1-\tau_{S}}}-\omega, \\
S=\frac{(2 \gamma+\delta)(\omega-\phi N)}{(1+\delta+2 \gamma) \frac{1-\tau_{S}}{1-\tau_{L}}-2 \gamma(1-c)} .
\end{gathered}
$$

Combining the above equations yields a joint equilibrium relation between fees and saving:

$$
F_{j}=F=S \cdot \frac{2 \gamma}{2 \gamma+\delta}(1-c)
$$

i.e., fixed fees are proportional to saving. This occurs because in our logarithmic utility specification saving is proportional to lifetime resources, and firms set fees based on willingness to pay, which is also proportional to lifetime resources. Combining fixed and variable fees, we see that total fee revenue per unit of saving $f$ is a constant that is independent of both $N$ and of whether we are under a Roth or Traditional system:

$$
f=f^{v}+F / S=\frac{2 \gamma+c \delta}{2 \gamma+\delta}
$$

This finding demonstrates that the assumption underpinning the results in Section 2 (that total fee revenue is proportional to saving) can emerge endogenously in a general equilibrium setting, even in the presence of fixed costs.

\subsubsection{Tax policy}

To satisfy its time- 0 budget constraint, the government borrows an amount $B$ at the market interest rate $r$ to cover its deficit, so that

$$
B=G+S \cdot \tau_{S}-(\omega+\Pi) \tau_{L} .
$$


To satisfy its time- 1 budget constraint, the government taxes retirement income at a rate $\tau_{R}$ :

$$
B(1+r)=\left[S\left(1-f^{v}\right)-F\right](1+r) \tau_{R},
$$

where $f^{v}$ and $F$ are the equilibrium values. Putting these together yields the government's single (intertemporal) budget constraint:

$$
G=(\omega+\Pi) \tau_{L}-\left(F / S+f^{v}\right) \cdot\left(\tau_{R} \cdot S\right)-S\left(\tau_{S}-\tau_{R}\right),
$$

where $G$ is government expenditure and the right-hand side is the present value of tax revenue.

Under Roth, both $\tau_{S}$ and $\tau_{R}$ equal zero. Because the government receives no revenue at time 1, it cannot borrow $\left(B^{R o t h}=0\right)$. Its only option is to balance the budget at time 0 by setting the tax rate on labor income equal to the ratio of government expenditure to the sum of wages and profits:

$$
\tau_{L}^{R o t h}=G /\left(\omega+\Pi^{R o t h}\right) .
$$

Under Traditional, $\tau_{S}=\tau_{L}$, so government revenue has three terms: the tax on labor income and profits, minus the fixed and variable fees it pays on its implicit account, minus the implicit government match on saving. The government has two policy variables (the labor income tax rate $\tau_{L}^{\text {Trad }}$ and the retirement income tax $\tau_{R}^{\text {Trad}}$ ), and one intertemporal budget constraint (39), leaving it with one degree of freedom. To simplify comparison between the two account types, we assume that $\tau_{L}^{T r a d}=\tau_{R}^{T r a d}$ so that $\tau_{M}^{T r a d}=0$, i.e. the implicit extra government match on Traditional due to differences in tax rates is zero.

Using the equations for optimal fees (27) and (36), optimal saving (34), and the expression for aggregate profits (33), we obtain:

$$
\begin{gathered}
\tau_{L}^{\text {Roth }}=\frac{(G / \omega)(1+\delta+2 c \gamma)}{(1+\delta+2 \gamma)(1-N \cdot \phi / \omega)-2(1-c) \gamma \cdot G / \omega} \\
\tau_{L}^{\text {Trad }}=\frac{(G / \omega)(1+\delta+2 c \gamma)}{[1+\delta(1-c)](1-N \cdot \phi / \omega)}
\end{gathered}
$$

It is easy to show with some algebra that, for a given $N, \tau_{L}^{\text {Trad }}>\tau_{L}^{\text {Roth }}$ if $c=0$, and for a given $N$ such that profits under Roth are nonnegative, if $c>0 .{ }^{52}$

\footnotetext{
${ }^{52}$ If profits under Roth are negative, it is possible for a lower tax rate to result in higher tax revenue.
} 


\subsubsection{Comparison of equilibrium quantities at fixed $N$}

At any given number of firms $N$, one can see from (32)-(34) that Traditional has higher assets under management, higher total variable fees $\left(f^{v} \cdot S\right)$, a higher fixed fee, and higher profits than Roth. The intuition is that at any given fee level the individual is less sensitive to fixed fees under Traditional than under Roth (i.e., for a given level of profit, the second term of (26) is less negative), because under Traditional the government is effectively paying a fraction $\tau_{R}$ of the fixed fee.

\subsubsection{Entry}

Next, we examine the entry decision. For any given $N$, the marginal firm exits if its profits are negative and enters if profits are positive conditional on entry. For example, if we start with $N$ such that profits are positive, entry causes $N$ to increase, and the resulting added competition and higher aggregate fixed costs together cause equilibrium fixed fees $(F)$, saving $(S)$, and aggregate profits (П) to fall. (This is formally shown in Section 1 of the Internet Appendix).

Since we assume that $N$ can be noninteger, firms enter the market until equilibrium profits $\pi_{j}$ equal zero, $j=1,2, \ldots N$. Equation (33) then implies that

$$
N=\frac{\omega}{\phi} \cdot \frac{2 \gamma(1-c)}{1+\delta+2 \gamma} \cdot \frac{1-\tau_{L}}{1-\tau_{S}}
$$

The share of employment in the asset management industry $(L)$ is found by substituting (43) and (34) into (7):

$$
L \equiv \frac{\phi N+c S}{\omega}=\frac{c \delta+2 \gamma}{1+\delta+2 \gamma} \cdot \frac{1-\tau_{L}}{1-\tau_{S}}
$$

\subsubsection{Taxes and equilibrium quantities with entry}

In an equilibrium with free entry and zero profits, equation (40) implies $\tau_{L}^{\text {Roth }}=G / \omega$. Continuing to assume $\tau_{M}^{\text {Trad }}=0$ (i.e., $\tau_{L}^{\text {Trad }}=\tau_{R}^{\text {Trad }}$ ), and substituting (43) into (42), we obtain ${ }^{53}$

$$
\tau_{L}^{T r a d}=\tau_{R}^{T r a d}=G / \omega\left(1+\frac{c \delta+2 \gamma}{1+\delta(1-c)}\right)>G / \omega=\tau_{L}^{R o t h} .
$$

\footnotetext{
${ }^{53}$ Note that the constraint $\tau_{L}^{T r a d}<100 \%$ implies a limit on the public expenditure share of output $G / \omega$ that is tighter than Roth. The higher $\gamma$, the higher the fees individuals are willing to pay, the larger the government's transfer to asset managers, and the fewer resources available for public expenditure.
} 
Thus, tax rates on labor income need to be higher under Traditional than under Roth, in order to pay for the extra asset management fees the government is incurring under Traditional. Note that since tax rates do not depend on $\phi$, total expenditure within each system on the fixed costs of asset management $=\phi \cdot N$ are independent of the size of the fixed cost $\phi$, because an increase in $\phi$ causes an offsetting decrease in $N$.

Moreover, under Traditional, the equilibrium saving, fixed fees, total fees, number of firms, saving, and employment in the asset management industry are all equal to their corresponding values under Roth, scaled up by a factor $1 /\left(1-\tau_{L}^{\text {Roth }}\right)>0$ :

$$
\frac{S^{\text {Trad }}}{S^{\text {Roth }}}=\frac{F^{\text {Trad }}}{F^{\text {Roth }}}=\frac{F^{\text {Trad }}+f S^{\text {Trad }}}{F^{\text {Roth }}+f S^{\text {Roth }}}=\frac{N^{\text {Trad }}}{N^{\text {Roth }}}=\frac{S^{\text {Trad }}}{S^{\text {Roth }}}=\frac{L^{\text {Trad }}}{L^{\text {Roth }}}=\frac{1}{1-\tau_{L}^{\text {Roth }}}>1,
$$

and consumption under Traditional is proportionately lower than under Roth because of the higher taxation under Traditional arising from the higher costs, both variable and fixed: ${ }^{54}$

$$
\frac{C_{0}^{\text {Trad }}}{C_{0}^{\text {Roth }}}=\frac{C_{1}^{\text {Trad }}}{C_{1}^{\text {Roth }}}=\frac{1-\tau_{L}^{\text {Trad }}}{1-\tau_{L}^{\text {Roth }}}=\frac{1-G / \omega \cdot \frac{1+\delta+2 \gamma}{1+\delta(1-c)}}{1-G / \omega}<1 .
$$

\subsection{Roth vs Traditional: Welfare analysis}

We denote welfare, defined in (12), as

$$
U^{k}=\ln C_{0}^{k}+\delta \ln C_{1}^{k}+\gamma \ln N^{k}+\gamma(1+\ln 2),
$$

where $k \in\{*, \operatorname{Roth}, \operatorname{Trad}\}$ indicates the respective quantities under the planner solution $\left(U^{*}\right)$, and the market equilibria with entry under Roth $\left(U^{\text {Roth }}\right)$ and Traditional $\left(U^{\text {Trad }}\right)$, respectively. The last term $[\gamma(1+\ln 2)]$ is a constant which we henceforth omit for brevity.

\footnotetext{
${ }^{54}$ One can easily see that in the absence of asset management costs (and thus fees), the benchmark equivalence result in Section 2.2 holds in our general equilibrium model. Setting $c=0$ (variable costs equal 0 ) and taking the limit as $\gamma \rightarrow 0$ (so that individuals do not care about distance and the number of firms and thus fixed costs gets arbitrarily close to zero), yields $\tau_{L}^{\text {Trad }}=\tau_{L}^{R o t h}$, and $C_{0}^{\text {Trad }}=C_{0}^{\text {Roth }}, C_{1}^{\text {Trad }}=C_{1}^{\text {Roth }}$, so that individuals are indifferent between Traditional and Roth.
} 
We begin by comparing social welfare under Roth and Traditional: ${ }^{55}$

$$
\begin{gathered}
U^{\text {Trad }}-U^{\text {Roth }}=\ln \left(C_{0}^{\text {Trad }} / C_{0}^{\text {Roth }}\right)+\delta \ln \left(C_{1}^{\text {Trad }} / C_{1}^{\text {Roth }}\right)+\gamma \ln \left(N^{\text {Trad }} / N^{\text {Roth }}\right) \\
=(1+\delta) \ln \left(\frac{1-\tau_{L}^{\text {Trad }}}{1-\tau_{L}^{\text {Roth }}}\right)+\gamma \ln \left(\frac{1}{1-\tau_{L}^{\text {Roth }}}\right)<0 .
\end{gathered}
$$

The two terms of (49) have different signs. The first term is negative because higher total asset management costs under Traditional relative to Roth lead to higher taxes in the model, resulting in proportionally lower consumption and welfare under Traditional. However, the second term is positive because Traditional also generates a larger number of asset management firms in the model, decreasing average distance and contributing to higher welfare. In Section 1 of the Internet Appendix, we prove that the sum of the two terms is always negative, i.e. the first term always dominates the second, so that social welfare in the model is always lower under Traditional than Roth. ${ }^{56}$ This result is obvious if all costs are variable, but it holds even if all costs are fixed $(c=0)$.

To understand this result, note that (17) and (43) imply

$$
N^{\text {Roth }} / N^{*}=1+\frac{1+\delta}{1+\delta+2 \gamma}>1
$$

i.e. the number of firms under the Roth equilibrium is strictly greater than under the planner, and welfare in the model is correspondingly lower. If, under Roth, $N$ were equal to $N^{*}$, firms would make positive profits, ${ }^{57}$ which would then induce additional firms to enter. This is the well-known “business-stealing” effect (Mankiw and Whinston, 1986): if an entrant causes incumbents to reduce output, entry is more desirable to the entrant than it is to society, resulting in a tendency toward excessive entry. The equilibrium under Traditional has even more firms than under Roth. This

\footnotetext{
${ }^{55}$ Note that a Roth ("TEE") account in our model is always better than a standard Taxable account ("TTE") even without behavioral frictions. This is shown in Section 1 of the Internet Appendix. Without fees, the optimal tax rate on investment returns $\tau_{I}^{*}$ in the model is zero, because $\tau_{I} \neq 0$ distorts the Euler equation. With fees, somewhat counterintuitively, $\tau_{I}^{*}<0$. A negative tax rate on investments forces the government to raise the tax rate on labor $\tau_{L}$ to balance the budget. This reduces saving, and therefore the number of firms, increasing welfare in the model. For small negative values of $\tau_{I}$, this effect more than compensates for the distortion induced in the Euler equation.

${ }^{56}$ In Section 1 of the Internet Appendix we show that Roth has higher social welfare in the model than Traditional for given $N$, for endogenous $N$ with free entry, and even if the government can choose $\tau_{L}^{T r a d}$ and $\tau_{R}^{T r a d}$ optimally, resulting in a slightly increasing time path of tax rates $\left(\tau_{R} \geq \tau_{L}\right.$, holding with equality if $\left.c=0\right)$.

$\left.{ }^{57} \Pi^{\text {Roth }}\right|_{N=N^{*}}=(\omega-G)(1-c) \gamma /(1+\delta+\gamma)>0$, where $\left.\Pi^{\text {Roth }}\right|_{N=N^{*}}$ indicates conditional profit evaluated at $N=N^{*}$. The notation $\left.\Pi^{\text {Roth }}\right|_{N}$ is used to explicitly distinguish profit conditional on a given value of $N$ as in equation (33) from the equilibrium profit $\left.\Pi^{\text {Roth }} \equiv \Pi^{\text {Roth }}\right|_{N=N^{R o t h}}$.
} 
effect, together with an unaltered Euler equation for consumption (and higher total variable costs if $c>0$ ), generates lower welfare in the model under Traditional than under Roth.

To provide further intuition, we take a log approximation of (49) and substitute in the values for $\tau_{L}^{\text {Trad }}$ and $\tau_{L}^{\text {Roth }}$ to yield $U^{\text {Trad }}-U^{\text {Roth }} \approx-G / \omega \cdot\{[(1+\delta) /(1+\delta-\delta c)] \cdot(\delta c+2 \gamma)-\gamma\}$. Even in the absence of variable costs $(c=0), U^{\text {Trad }}-U^{\text {Roth }} \approx-G / \omega \cdot \gamma$ is clearly negative. ${ }^{58}$ In this case, since the extra assets associated with Traditional generate no additional costs, it may appear that under Traditional each firm could simply absorb the extra assets and keep fixed and variable fees the same as they were under Roth, reducing overall fees as a percentage of assets under management and leaving profits unchanged at zero. In this case, there would be no additional resources devoted to asset management under Traditional and no welfare loss in the model. However, this is not a market equilibrium, because it is profit-maximizing for firms to charge higher fixed fees $F$ under Traditional (see Section 5.6.3). The resulting positive profits generate entry under Traditional, leading to correspondingly lower welfare in the model.

To better understand the role of fixed and variable costs, we decompose the welfare effect of switching from Traditional to Roth into two parts:

$$
U^{\text {Roth }}-U^{\text {Trad }}=\left(\left.U^{\text {Trad }}\right|_{N=N_{\text {Roth }}}-U^{\text {Trad }}\right)+\left(U^{\text {Roth }}-\left.U^{\text {Trad }}\right|_{N=N_{\text {Roth }}}\right),
$$

where $\left.U^{\text {Trad }}\right|_{N}$ is conditional aggregate welfare, i.e., the sum of all individual utilities in a market equilibrium under the Traditional scheme given an exogenous $N$, and therefore $\left.U^{\text {Trad }}\right|_{N=N \text { Roth }}$ is conditional aggregate welfare evaluated at $N=N^{\text {Roth }}$. Starting from a market equilibrium under Traditional, the first term on the right-hand side is the net effect from decreasing the number of firms to the Roth level, which can be further decomposed into two terms: the welfare gain from lower fixed costs, and the welfare loss from the increase in average distance between investors and their chosen firm. The second term is the welfare effect in the model of switching to Roth while leaving $N=N^{\text {Roth }}$. This second step causes assets under management (and hence variable costs) to decrease, but leaves the number of firms (and hence fixed costs) unchanged, and therefore we

\footnotetext{
${ }^{58}$ For $c \geq 0$, this approximate expression is a decreasing function of $c$ (i.e., higher $c$ implies $U^{\text {Trad }}-U^{\text {Roth }}$ is more negative). Indeed, $U^{\text {Trad }}-U^{\text {Roth }}$ is negative even for some $c<0$, e.g. if net aggregate alpha after variable costs is positive, as is assumed for instance in Berk and Green (2004) (ignoring for simplicity the possibility that either gross alpha or costs vary with fund size).
} 
define this term as the gain from lower variable costs.

Substituting the appropriate equilibrium values into (51) and simplifying, we obtain

$$
\underbrace{U^{\text {Roth }}-U^{\text {Trad }}}_{\begin{array}{c}
\text { Effect of } \\
\text { switch to Roth }
\end{array}}=\underbrace{(1+\delta) \ln \frac{1-G / \omega}{1-G / \omega \cdot(\tilde{A}-\tilde{B})}}_{\begin{array}{c}
\text { Gain from lower } \\
\text { variable costs }
\end{array}}+\underbrace{(1+\delta) \ln \frac{1-G / \omega \cdot(\tilde{A}-\tilde{B})}{1-G / \omega \cdot \tilde{A}}}_{\begin{array}{c}
\text { Gain from lower } \\
\text { fixed costs }
\end{array}}+\underbrace{\gamma \ln (1-G / \omega)}_{\begin{array}{c}
\text { Loss from } \\
\text { fewer firms }
\end{array}},
$$

where $\tilde{A}=(1+\delta+2 \gamma) /[1+\delta(1-c)]$ and $\tilde{B}=2 \gamma(1-c) /(1+\delta+2 c \gamma)$.

In Section 1 of the Internet Appendix we also examine the case in which firms are restricted to charge only fixed fees or only variable fees. The resulting potential mismatch between cost structure and fee structure creates an additional friction in the model, affecting our welfare analysis. However, we show that under reasonable calibrations a switch from Traditional to Roth in the model is still welfare-enhancing.

\subsection{Calibration}

We now carry out three calibration exercises based on our model. The results are in Table 6.

In our first exercise, we quantify the welfare gain in the model of a switch from Traditional to Roth expressed as a percent of retirement consumption. Specifically, we define $\alpha$ as the fraction of retirement consumption that could be taken away under Roth such that aggregate utility would be the same as under Traditional. ${ }^{59}$ In other words, we solve for $\alpha$ such that

$$
\ln C_{0}^{T r a d}+\delta \ln C_{1}^{\text {Trad }}-\gamma \ln d_{i, j}^{\text {Trad }}=\ln C_{0}^{\text {Roth }}+\delta \ln \left[C_{1}^{\text {Roth }}(1-\alpha)\right]-\gamma \ln d_{i, j}^{\text {Roth }} .
$$

The right hand side can be rewritten as $U^{\text {Roth }}+\delta \ln (1-\alpha)$, which implies we want to solve for $\alpha$

\footnotetext{
${ }^{59} \mathrm{~A}$ switch would result in higher tax rates for all individuals and an increase in the number of firms. If firms change positions on the circle and individuals do not, most individuals would find themselves at a lower distance from the closest firm but some would be farther. In that case, to make every individual indifferent, a customized (and possibly negative) fraction of consumption $\alpha_{i}$ would have to be taken away from each. However, individuals' positions can be rearranged so that each individuals' distance from the closest firm is a constant fraction of the original distance, making $\alpha_{i}=\alpha$ for all individuals.
} 


\begin{tabular}{lccccc}
\hline$c / f$ & $\mathbf{0 \%}$ & $\mathbf{2 5 \%}$ & $\mathbf{5 0 \%}$ & $\mathbf{7 5 \%}$ & $\mathbf{1 0 0 \%}$ \\
\hline$c$ (annualized, bps) & 0 & 18 & 38 & 58 & 80 \\
$\gamma$ & 0.087 & 0.065 & 0.043 & 0.022 & 0.000 \\
\hline$\alpha$ (Equiv. retirement consumption) & $0.76 \%$ & $0.86 \%$ & $0.96 \%$ & $1.06 \%$ & $1.15 \%$ \\
$\ldots=$ Gain from lower variable costs & $0.00 \%$ & $0.35 \%$ & $0.65 \%$ & $0.92 \%$ & $1.15 \%$ \\
$\ldots$. Gain from lower fixed costs & $1.35 \%$ & $0.96 \%$ & $0.60 \%$ & $0.28 \%$ & $0.00 \%$ \\
$\ldots-$ Loss from fewer firms & $0.59 \%$ & $0.45 \%$ & $0.30 \%$ & $0.15 \%$ & $0.00 \%$ \\
\hline$\alpha /$ (Tax Exp.\%) & $23.6 \%$ & $26.8 \%$ & $30.0 \%$ & $33.1 \%$ & $36.1 \%$ \\
\hline$\tau_{M}$ (Equivalent saving match) & $6.08 \%$ & $6.06 \%$ & $6.03 \%$ & $6.00 \%$ & $5.97 \%$ \\
$\ldots=$ Compensating match & $3.04 \%$ & $2.34 \%$ & $1.59 \%$ & $0.82 \%$ & $0.00 \%$ \\
$\ldots+$ Welfare-enhancing match & $3.04 \%$ & $3.72 \%$ & $4.44 \%$ & $5.19 \%$ & $5.97 \%$ \\
\hline
\end{tabular}

Table 6: Calibration. $\alpha$ is the percent drop in retirement consumption that would be needed to eliminate the welfare gain in the model due to a switch from Traditional to Roth, as defined by equation (54). Its three components are shown in equation (52). $\alpha$ is adjusted to reflect the fact that retirement account payouts are roughly 1/5 of retirees' consumption. $\alpha /$ (Tax Exp.\%) is unadjusted $\alpha$ scaled by the tax expenditure on retirement accounts, also expressed as a percent of retirement consumption. $\tau_{M}$ is the match the government can afford upon a switch from Traditional to Roth leaving taxes unchanged, defined by equation (55). Its first component is defined in equation (56), and the second as the residual. Each column assumes a different value of $c / f$, i.e., $c / f=0 \%$ means that all costs of asset management are fixed, and $c / f=100 \%$ implies that all costs are variable. $\gamma$ is then derived from equation (36).

such that $\delta \ln (1-\alpha)=U^{\text {Trad }}-U^{\text {Roth }}$. This yields

$$
-\ln (1-\alpha)=\frac{1}{\delta}\left(U^{\text {Roth }}-U^{\text {Trad }}\right)=\frac{\log \left(1-\tau_{L}^{\text {Roth }}\right)^{1+\delta+\gamma}-\log \left(1-\tau_{L}^{\text {Trad }}\right)^{1+\delta}}{\delta} .
$$

Since $-\ln (1-\alpha) \approx \alpha$, the right-hand side of equation (54) represents the consumption-equivalent welfare gain of Roth in the model. Since our approximate expression for $\alpha$ is simply ( $U^{\text {Roth }}-$ $\left.U^{T r a d}\right) / \delta$, the welfare gain decomposition of equation (52) can also be applied to $\alpha$.

To calibrate $\alpha$, we require estimates of $\delta, G / \omega, c$, and $\gamma$. We set $G / \omega=20 \%$, a rough estimate of public expenditure as a fraction of domestic output, and $\delta=0.64$, an annual $1.5 \%$ real discount rate over a horizon of $T=30$ years. We set total percentage fees $f=f^{v}+F / S=21.4 \%$, corresponding to the value of $80 \mathrm{bps} / \mathrm{year}$ that we estimated in Section 4 over the same horizon. Under this assumption on $f$, and given $\delta$, the fee equation (36) $f=(2 \gamma+c \delta) /(2 \gamma+\delta)$ implies 
a relation between $c$ and $\gamma$. We examine a range of values for $c$ such that $c / f$ varies between $0 \%$ and $100 \%$, and we let $\gamma$ vary accordingly. ${ }^{60}$ Our estimated $\alpha$ adjusts for the fact that, unlike in the model, tax-deferred retirement account payouts finance only about 1/5 of total retirees' consumption, and therefore that the welfare gain in the model from a switch to Roth should be scaled down accordingly. ${ }^{61}$ Thus adjusted, $\alpha$ is a substantial number regardless of cost structure, varying between $0.76 \%$ and $1.15 \%$ of retirement consumption. ${ }^{62}$ Table 6 also breaks down the calibrated values of $\alpha$ based on the decomposition of equation (52). Regardless of the relative importance of fixed costs, the gain from the lower fixed costs under Roth is roughly double the loss from having fewer firms. To this net gain one must add the gain from variable costs due to the lower assets under Roth. The greater the importance of variable costs, the higher the welfare gain of Roth accounts in the model; $c / f=100 \%$ (all variable costs) corresponds to the fixed-percentage-fee model of Section 2.

In our second exercise, we scale $\alpha$ by the overall tax expenditure on retirement savings accounts under Roth. ${ }^{63}$ We define tax expenditure in the model $(T X)$ as the additional revenue (expressed in future value at time 1) that the government would receive if it eliminated the tax break on retirement saving, so that the returns on saving were all taxable, but everything else (first period consumption, number of firms, etc) stayed the same. We then express this quantity as a percent of retirement consumption $(T X \%)$. Using the definitions of $f, F$, and $S$, we obtain $T X \%=r \tau_{I} /\left(1+r\left(1-\tau_{I}\right)\right)$,

\footnotetext{
${ }^{60}$ As fixed costs vanish $(c / f \rightarrow 1), \gamma$ must go to zero to keep $f=80$ bps. In this case, the number of firms $N$ goes to zero as well. Algebraically, the model allows for $N=0$. Conceptually, it is difficult to imagine individuals paying fees and society incurring (variable) costs in a world with zero firms. One can loosely interpret this scenario as $N$ as being a large number under normal conditions and becoming very small as $\gamma \rightarrow 0$.

${ }^{61}$ Total DC + IRA payouts in 2016, the latest year available from the ICI retirement Market statistics were $\$ 699.5$ billion, of which the Roth fraction is negligible. To this figure, we apply the tax rate of $25.8 \%$ estimated above in footnote 28. For the same year, the Bureau of Economic Analysis reports aggregate personal consumption expenditure of $\$ 12,748$ billion. Based on the 2018 Bureau of Labor Statistics' Consumer Expenditure Survey, 20.8\% of total consumption can be traced to units whose reference person is 65 years or older. The fraction of retirement consumption financed by retirement account payouts is therefore $699.5 \cdot(1-0.259) /(12,748 \cdot 0.208)=.1955 \approx 1 / 5$.

${ }^{62}$ The value in the last column $(1.15 \%)$ is not directly comparable with our Section 4 estimate that the U.S. government loses $\$ 20.7$ billion a year in tax revenue (approximately $0.55 \%$ of retirement consumption). To obtain comparable estimates would require constructing an overlapping-generations model and taking a cross-section of retirement saving at a point in time.

${ }^{63}$ No adjustment is needed to this measure because tax expenditure is expressed in the same units as unadjusted $\alpha$ (percent of retirement consumption).
} 
where $\tau_{I}$ is the tax rate on investment income generated on taxable accounts. ${ }^{64}$ To calibrate $T X \%$, we set $r=56 \%$, a $1.5 \%$ real return for $T=30$ years, and $\tau_{I}=39.1 \%$, a rough approximation of the long-run effect of personal taxes on real returns, ${ }^{65}$ obtaining $T X \%=16.4 \%$, i.e., $16.4 \%$ of retirement wealth of an individual who has saved in a retirement saving account is the result of not having paid taxes on returns. Then, depending on cost structure assumptions, the consumptionequivalent welfare gain of Roth relative to Traditional in the model is equal to about one-quarter to one-third of the total tax expenditure on Roth retirement accounts!

In our third and last exercise, we start from a zero-profit world with Traditional accounts and assume that, upon a switch to Roth, $\tau_{L}$ remains the same. That is, we assume that the tax rate on labor income under Roth is $G / \omega\{1+(c \delta+2 \gamma) /[1+\delta(1-c)]\}$ as in equation (45). In this case, leaving everything else the same, the government will have a budget surplus under Roth. We assume that the government uses this surplus to provide an explicit match $\tau_{M}^{\text {Roth }}>0$ to those who save in a Roth account (e.g., if $\tau_{M}^{\text {Roth }}=5 \%$, for every $\$ 100$ contributed, the government adds an extra $\$ 5$ into the account). This match is 66

$$
\tau_{M}^{\text {Roth }}=\frac{2 \gamma+\delta c}{2 \gamma+\delta} \cdot \frac{\tau_{L}^{\text {Trad }}}{1-\tau_{L}^{\text {Trad }}}>0 .
$$

A fraction of this match compensates individuals for the lower number of firms upon the switch:

$$
\tau_{M}^{C o m p}=\left(1-\tau_{L}^{T r a d}\right)^{-\gamma /(\delta+\gamma)}-1
$$

\footnotetext{
${ }^{64}$ In practice, taxation is based on nominal investment income. Since all variables in the model are real, $\tau_{I}$ is the effective tax rate on real returns, which depends on the level of inflation.

${ }^{65} \mathrm{We}$ assume the annual tax on all capital income to be $\tau_{I}^{\text {Annual }}=20 \%$. We define nominal returns as $R=$ $(1+r)(1+i)-1$, where $i=56 \%$ based on a $1.5 \%$ inflation rate for $T=30$ years. Since interest and dividends are taxed every year, whereas capital gains are taxed once when the asset is sold, the long-run effect is different. For interest and dividend income, we define the effective tax rate to be $\tau_{I}^{\text {Div } / \text { Int }}=1-\left[1+R\left(1-\tau_{I}^{\text {Annual }}\right)\right]^{T} /(1+R)^{T}$, and for capital gains we define the effective tax rate to be $\tau_{I}^{\text {Gain }}=\tau_{I}^{\text {Annual }}\left[(1+R)^{T}-1\right] /(1+R)^{T}$. The effective long-run tax rate on investment income is then a weighted average of the two rates, $\tau_{I}=w \cdot \tau_{I}^{\text {Gain }}+(1-w) \cdot \tau_{I}^{\text {Div } / \text { Int }}$, where $w=48 \%$ is calibrated based on Internal Revenue Service Statistics of Income data using average fractions of interest, dividend and capital gain income from 1990 to 2016.

${ }^{66}$ To find $\tau_{M}^{R o t h}$ we solve for the $\tau_{S}^{R o t h}$ that balances the government's budget constraint. Under Roth $\left(\tau_{R}=0\right)$ and with entry $(\Pi=0)$, the government's budget constraint is $G=\omega \tau_{L}-S \tau_{S}$. Equations (34) and (43) imply $S=\omega(2 \gamma+\delta) /(1+\delta+2 \gamma) \cdot\left(1-\tau_{L}\right) /\left(1-\tau_{S}\right)$. We solve for $\tau_{S}$ and then substitute in the expression for $\tau_{L}$ from (45) which yields $\tau_{S}^{\text {Roth }}=(2 \gamma+c \delta) /\left[(G / \omega)^{-1}(1+\delta+2 \gamma)^{-1}(2 \gamma+\delta)(1+\delta(1-c))-\delta(1-c)\right]$ and then use the existing definition $\tau_{M} \equiv\left(\tau_{S}-\tau_{R}\right) /\left(1-\tau_{S}\right)$.
} 
The remainder of the match generates a net improvement in welfare in the model. The calibrated values of $\tau_{M}^{\text {Roth }}$ and its components are reported in the bottom row of Table 6. A switch from Traditional to Roth leaving tax rates unchanged would allow the government to provide a roughly $6 \%$ match on all retirement saving, regardless of whether asset management costs are primarily fixed or variable. If all costs are variable, the entirety of the match generates a net welfare improvement in the model. If all costs are fixed, this $6 \%$ match is still 3\% in excess of what would be needed to compensate for the lower number of firms under Roth. Note that this result is obtained in an equilibrium model in which Traditional is assumed to have no implicit match, i.e., tax rates during work and retirement are the same. If Traditional did have an implicit match $\left(\tau_{L}^{\text {Trad }}>\tau_{R}^{\text {Trad }}\right)$, then upon a switch to Roth the government would be able to offer an even larger explicit match $\left(\tau_{M}^{\text {Roth }} \geq\left(\tau_{L}^{\text {Trad }}-\tau_{R}^{\text {Trad }}\right) /\left(1-\tau_{L}^{\text {Trad }}\right)\right) \cdot{ }^{67}$

\section{Conclusion}

Under some simplifying assumptions about tax rates, a standard benchmark model yields an equivalence result between front-loaded (Roth) and back-loaded (Traditional) taxation of retirement savings. Individuals' consumption in each period is the same under Roth as under Traditional, and the present value of government tax revenues is the same under the two systems. However, the timing of taxation is different, and as a result back-loaded taxation leads to higher outstanding government debt and a correspondingly greater amount of retirement assets. These additional assets represent an implicit government portfolio, i.e., resources earmarked to pay future taxes when the money is distributed from the account. In this paper, we add one crucial bit of realism to the benchmark model: asset management fees. We show that the equivalence result breaks down because the government is paying an estimated $\$ 20.7$ billion a year in fees on its $\$ 3$ trillion implicit portfolio. These assets represent added demand for asset management services.

We also develop a stylized general equilibrium model to examine how this added demand affects

\footnotetext{
${ }^{67}$ For a small tax wedge $\left(\tau_{L}^{\text {Trad }}-\tau_{R}^{\text {Trad }}\right)$, the combined explicit match would be approximately equal to the sum of the match in Table 6 and the explicit match based on the tax wedge.
} 
equilibrium fees, real resources devoted to asset management, and asset management profit. We show that welfare in that model is lower under Traditional than under Roth because back-loading taxation inefficiently increases the amount of resources spent on asset management. The size of the welfare loss depends on the degree to which asset management costs are fixed or variable. With only variable costs, the partial equilibrium cost results apply in general equilibrium, and all of the extra costs generate welfare losses. At the other extreme, when all costs are fixed, because the government effectively pays part of the fees under Traditional and because firms have market power, firms charge higher total dollar fees under Traditional than under Roth, resulting in higher profits for the asset management industry. With firm entry, the higher profits under Traditional lead to a greater number of firms, and thus inefficiently high aggregate resources devoted to asset management. Regardless of the importance of fixed costs, the overall welfare cost in the model is substantive, ranging between $0.76 \%$ and $1.15 \%$ of retirement consumption. This welfare cost represents about $1 / 4$ to $1 / 3$ of the government's tax expenditure on subsidizing retirement saving. We also show that a switch from Traditional to Roth that leaves tax rates unchanged would enable the government to offer an explicit match (as is done for Lifetime ISAs in the United Kingdom) equal to about $6 \%$ of all Roth contributions. This is separate from the explicit match that could be implemented under Roth to replicate the implicit match under Traditional due to any tax rate differentials between working and retirement years.

Our results raise the policy issue of whether governments should encourage or possibly mandate wider adoption of Roth. Our model highlights one advantage of such a switch. However, both the benchmark model and our model abstract from other potential drivers of the policy choice between front-loaded and back-loaded taxation of retirement savings.

First, most real-world tax systems have a progressive schedule with marginal tax rates that are increasing in income, which generates both cross-section heterogeneity and uncertainty in marginal and average tax rates (Brown et al., 2017). Progressive taxes complicate the analysis in that a shift to Roth could (i) generate distributional consequences due to differences in the implicit Traditional match across individuals that could be hard to replicate with an explicit Roth match, (ii) cause 
lifetime taxes to become less aligned with lifetime income ${ }^{68}$, and (iii) reduce the potential insurance value that arises under Traditional because the average tax rate on distributions is higher when the account balance is higher.

Second, behavioral biases that cause people to save too little are a frequently-cited motive for the provision of retirement saving incentives and could affect the relative desirability of the two systems. Behavioral arguments cut both ways. If workers ignore or underestimate the future "tax bite" under back-loaded taxation, income effects (individuals feel wealthier) would lead to higher working-age consumption and lower retirement consumption than front-loaded taxation (Iwry and John, 2009). However, back-loaded taxation could also lower working-age consumption through substitution effects (future consumption feels cheaper) because of the "instant gratification" of an immediate tax benefit from saving (Feenberg and Skinner, 1989). Beshears et al. (2017) find empirically that Roth induces individuals to save more, and argue that this is because individuals underweight future taxes and focus on dollar contributions and saving rather than on consumption. ${ }^{69}$ In addition, during the individual's retirement, under progressive taxation a Traditional system penalizes large withdrawals with higher tax rates. As part of the recent British debate, an Economist editorial claims that this feature "is actually quite useful in that it stops people blowing their pension pot in a spending spree at 65" (Buttonwood, 2015). Of course, the other side of the coin is that Traditional penalizes individuals who withdraw funds in bulk for legitimate reasons such as hardship or investment. We are not aware of any systematic study of this tradeoff.

Third, there are political economy considerations that are important to the debate over a shift from Traditional to Roth. U.S. budget rules make it more cumbersome to pass bills that increase the

\footnotetext{
${ }^{68}$ For example, consider two workers with the same lifetime income: one with high annual earning and a short work life (e.g. a firefighter), and another with lower annual earnings but a longer work life (e.g. a librarian). Under Roth, the firefighter would pay more lifetime taxes than the librarian. Under Traditional, the gap between the lifetime taxes paid by the two workers will shrink and potentially disappear.

${ }^{69}$ Our results rely on the assumption that, for a given level of tax rates, individuals rationally adjust their contributions to ensure that retirement consumption would be the same under Roth and Traditional. If Beshears et al.'s findings generalized to the policy experiments we consider, they would complicate our welfare analysis, but the gist of our argument would still be valid. Roth is more cost effective than Traditional. If the total amount of assets is constant under Traditional and Roth, then Roth delivers a larger savings subsidy for the same cost to the government. At the other extreme, if, as in our paper, the total amount of retirement consumption is constant, then Roth delivers the same savings subsidy for a lower cost to the government.
} 
total budget deficit over a five- or ten-year window. A transition from Traditional to Roth generates more cash flow upfront and less when the relevant workers retire, thus bringing more revenue into the budget window, resulting in a temporary deficit reduction which could ease the passage of other legislation that involved lower taxes or higher spending. ${ }^{70}$ This additional short-run fiscal flexibility may or may not be considered desirable, but it certainly makes Roth attractive to many real-world policymakers. Indeed, one of the purported motivations for originally proposing Roth accounts in the U.S. was to help "fund" cuts in the capital gains tax (Pine, 1989).

Finally, part of our contribution is to highlight that currently, the U.S. government indirectly owns about $\$ 2$ trillion in equities via tax-deferred retirement accounts. This added equity exposure could be beneficial if the government desired it and were unable to obtain it in a more direct and cost-effective way, but it could lead to excess equity exposure as well. We have no evidence that this is a conscious policy choice, let alone one that has been publicly debated.

Our analysis raises some additional policy issues. One way to reduce the cost of the implicit government account is to shrink or eliminate it by switching to Roth, as discussed throughout the paper. An alternative approach would be to remain with Traditional, but reduce the level of investment fees. An example of a policy aimed at this goal was the U.S. Department of Labor fiduciary rule implemented in June 2017 but subsequently struck down by the courts. One of the stated motivations for the rule was protecting individuals with retirement accounts from aggressive marketing of high-fee products - especially senior investors as they consider rolling over their employer plan savings into an individual retirement account. If a fiduciary rule had the effect of reducing fees incurred by individual investors, our results suggest that it would also reduce the resources devoted to asset management and increase the government's revenue (at any given level of tax rates), providing a possible additional rationale for implementing such a rule. ${ }^{71}$

\footnotetext{
${ }^{70}$ The effectiveness of this approach is complicated by the "Byrd rule," which requires a supermajority to approve any deficit increases that could occur beyond the period covered by the budget resolution. See the Committee for a Responsible Federal Budget's "Reconciliation 101" (http://www.crfb.org/papers/reconciliation-101).

${ }^{71}$ In our model, with free entry and zero profits, lowering fees while holding tax rates constant lowers the number of asset management firms, saves real resources, and increases government revenues. With restricted entry and positive profits, lowering fees increases Traditional balances (and thus taxable retirement income) and lowers profits by the same amount. If these two forms of income are taxed as the same rate, the government's revenue is unchanged. However, even in this case, a sufficiently large reduction in fees drives profits to zero and forces firms out of the market. As
} 


\section{References}

Abel, A.B., 2001. The effects of investing Social Security funds in the stock market when fixed costs prevent some households from holding stocks. American Economic Review 91, 128-148.

Aiyagari, S.R., McGrattan, E.R., 1998. The optimum quantity of debt. Journal of Monetary Economics 42, 447-469.

Anand, A., Irvine, P., Puckett, A., Venkataraman, K., 2012. Performance of institutional trading desks: An analysis of persistence in trading costs. Review of Financial Studies 25, 557-598.

Anderson, S.P., Renault, R., 1999. Pricing, product diversity, and search costs: A bertrandchamberlin-diamond model. RAND Journal of Economics 30, 719-735.

Auerbach, A., 2004. How much equity does the government hold? American Economic Review 94, 155-160.

Barclays, 2017. Bloomberg barclays index methodology. Retrieved at https://www. bbhub . io/indices/sites/2/2017/03/Index-Methodology-2017-03-17-FINAL-FINAL .pdf on $11 / 15 / 2017$.

Barro, R.J., 1974. Are government bonds net wealth? Journal of Political Economy 82, 1095-1117.

Ben-Rephael, A., Kandel, S., Wohl, A., 2011. The price pressure of aggregate mutual fund flows. Journal of Financial and Quantitative Analysis 46, 585-503.

Bergstresser, D., Chalmers, J.M.R., Tufano, P., 2009. Assessing the costs and benefits of brokers in the mutual fund industry. Review of Financial Studies 22, 4129-4156.

Berk, J., van Binsbergen, J., 2015. Measuring skill in the mutual fund industry. Journal of Financial Economics .

Berk, J.B., Green, R.C., 2004. Mutual fund flows and performance in rational markets. Journal of Political Economy 112, 1269-1295.

Beshears, J., Choi, J.J., Laibson, D., Madrian, B.C., 2017. Does front-loading taxation increase savings? evidence from Roth 401(k) introductions. Journal of Public Economics 151, 84-95.

Bessembinder, H., Jacobsen, S.E., Maxwell, W.F., Venkataraman, K., 2018. Capital Commitment and Illiquidity in Corporate Bonds. Journal of Finance 73, 1615-1661.

Bogle, J.C., 2014. The arithmetic of 'all-in' investment expenses. Financial Analysts Journal 70, $13-21$.

Bohn, H., 1990. Tax smoothing with financial instruments. The American Economic Review 80,

firms exit, the decrease in aggregate fixed costs offsets some or all of the revenue decline from lower fees, so that any decline in profits is smaller than the rise in government revenue from higher taxable retirement income, leading to an overall increase in government revenue. 
$1217-1230$.

Bolton, P., Santos, T., Scheinkman, J.A., 2016. Cream-skimming in financial markets. Journal of Finance 71, 709-736.

Brady, P., 2012. The tax benefits and revenue costs of tax deferral. Investment Company Institute, Washington, DC.

BrightScope, ICI, 2019. The BrightScope/ICI Defined Contribution Plan Profile: A Close Look at 401(k) Plans, 2016. Technical Report.

Brown, D.C., Cederburg, S., O'Doherty, M.S., 2017. Tax uncertainty and retirement savings diversification. Journal of Financial Economics 126, 689-712.

Burman, L., Gale, W.G., Weiner, D., 2001. The taxation of retirement saving: Choosing between front-loaded and back-loaded options. National Tax Journal 54, 689-702.

Busse, J.A., Chordia, T., Jiang, L., Tang, Y., 2018. Mutual fund trading costs. Available at SSRN: https://ssrn. com/abstract=2350583.

Buttonwood, 2015. EET your TEE, George. The Economist .

Carlin, B.I., 2009. Strategic price complexity in retail financial markets. Journal of Financial Economics 91, 278-287.

Che, J., Qian, Y., 1998. Insecure property rights and government ownership of firms. The Quarterly Journal of Economics 113, 467-496.

Chen, J., Hong, H., Huang, M., Kubik, J.D., 2004. Does fund size erode mutual fund performance? the role of liquidity and organization. American Economic Review 94, 1276-1302.

Choi, J., Huh, Y., 2017. Customer liquidity provision: Implications for corporate bond transaction costs. SSRN working paper. Retrieved at https://ssrn . com/abstract $=2848344$ on $11 / 15 / 2017$.

Christoffersen, S.E., Musto, D.K., 2002. Demand curves and the pricing of money management. Review of Financial Studies 15, 1499-1524.

Conrad, J.S., Johnson, K.M., Wahal, S., 2001. Institutional trading and soft dollars. Journal of Finance 56, 397-416.

Cooper, M., Halling, M., Yang, W., 2018. The persistence of fee dispersion among mutual funds. Available at https://ssrn. com/abstract=1456079.

Copeland, C., 2018. EBRI IRA database: Ira balances, contributions, rollovers, withdrawals, and asset allocation, 2016 update. EBRI Issue Brief 424.

Cremers, M., Ferreira, M.A., Matos, P., Starks, L., 2016. Indexing and active fund management: International evidence. Journal of Financial Economics 120, 539-560. 
Diamond, P., Geanakoplos, J., 2003. Social security investment in equities. American Economic Review 93, 1047-1074.

Dyck, A., Pomorski, L., 2011. Is bigger better? size and performance in pension plan management. Rotman School of Management Working Paper No. 1690724, available at http://ssrn.com /abstract=1690724.

Economides, N., 1989. Symmetric equilibrium existence and optimality in differentiated product markets. Journal of Economic Theory 47, 178-194.

Elton, E.J., Gruber, M.J., Busse, J.A., 2004. Are investors rational? choices among index funds. Journal of Finance 59, 261-288.

Fama, E.F., French, K.R., 2010. Luck versus skill in the cross-section of mutual fund returns. The Journal of Finance 65, 1915-1947.

Feenberg, D.R., Skinner, J., 1989. Sources of IRA saving. Tax Policy and the Economy 3, 25-46.

Gabaix, X., Gopikrishnan, P., Plerou, V., Stanley, H.E., 2006. Institutional investors and stock market volatility. Quarterly Journal of Economics 121, 461-504.

Gabaix, X., Laibson, D., 2006. Shrouded attributes, consumer myopia, and information suppression in competitive markets. Quarterly Journal of Economics 121, 505-540.

Gao, X., Livingston, M., 2008. The components of mutual fund fees. Financial Markets, Institutions and Instruments 17, 197-223.

Gârleanu, N.B., Pedersen, L.H., 2018. Efficiently inefficient markets for assets and asset management. Journal of Finance 73, 1663-1712.

Geanakoplos, J., Mitchell, O., Zeldes, S.P., 1999. Social Security Money's Worth. Pension Research Council, University of Pennsylvania Press. chapter 5. Prospects for Social Security Reform, pp. 79-151.

Gennaioli, N., Shleifer, A., Vishny, R., 2015. Money doctors. Journal of Finance 70, 91-114.

Gil-Bazo, J., Ruiz-Verdú, P., 2008. When cheaper is better: Fee determination in the market for equity mutual funds. Journal of Economic Behavior and Organization 67, 871-885.

Gil-Bazo, J., Ruiz-Verdú, P., 2009. The relation between price and performance in the mutual fund industry. The Journal of Finance 64, 2153-2183.

Goldstein, M.A., Hotchkiss, E.S., 2018. Providing Liquidity in an Illiquid Market: Dealer Behavior in U.S. Corporate Bonds. Journal of Financial Economics forthcoming.

Gong, Q., Liu, Q., Zhang, Y., 2016. Optimal product differentiation in a circular model. Journal of Economics 119, 219-252.

Greenwood, R., Scharfstein, D., 2013. The growth of finance. Journal of Economic Perspectives 
$27,3-28$.

Grossman, S.J., Stiglitz, J.E., 1980. On the impossibility of informationally efficient markets. American Economic Review 70, 393-408.

Heathcote, J., 2005. Fiscal policy with heterogeneous agents and incomplete markets. Review of Economic Studies 72, 161-188.

Henderson, B.J., Pearson, N.D., 2011. The dark side of financial innovation: A case study of the pricing of a retail financial product. Journal of Financial Economics 100, 227-247.

Holden, S., Duvall, J., Chism, E.B., 2019. The economics of providing 401(k) plans: Service, fees and expenses, 2018. ICI Research Perspective 24.

Holmström, B., Tirole, J., 1998. Private and public supply of liquidity. Journal of Political Economy $106,1-40$.

Hortacsu, A., Syverson, C., 2004. Product differentiation, search costs, and competition in the mutual fund industry: A case study of S\&P 500 index funds. Quarterly Journal of Economics , 403-456.

Hubbard, R.G., Koehn, M.F., Ornstein, S.I., Audenrode, M.V., Royer, J., 2010. The Mutual Fund Industry: Competition and Investor Welfare. Columbia Business School Publishing.

ICI, 2019. 2019 Investment Company Fact Book. Investment Company Institute. Available at https://www.ici.org/pdf/2019_factbook.pdf.

Ince, O., Kadlec, G.B., McKeon, S.B., 2018. Institutional counterparties and performance. Available at SSRN: https://ssrn.com/abstract=3172301.

Iwry, J.M., John, D.C., 2009. Pursuing universal retirement security through automatic IRAs. Brookings Institution, Retirement Security Project, Research Report 2009-3.

Kahn, V.M., 2002. Investing; mutual fund expertise, for rent. The New York Times .

Krishnamurthy, A., Vissing-Jorgensen, A., 2012. The aggregate demand for Treasury debt. Journal of Political Economy 120, 233-267.

Latzko, D.A., 1999. Economies of scale in mutual fund administration. Journal of Financial Research 22, 331-339.

Livingston, M., Zhou, L., 2015. Brokerage commissions and mutual fund performance. Journal of Financial Research 38, 283-303.

Lucas, D.J., Zeldes, S.P., 2009. How should public pension plans invest? American Economic Review 99, 527-532.

Lurie, I.Z., Ramnath, S.P., 2011. Long-run changes in tax expenditures on 401(k)-type retirement plans. National Tax Journal 64, 1025-1038. 
Malkiel, B.G., 2013. Asset management fees and the growth of finance. Journal of Economic Perspectives 27, 97-108.

Mankiw, N.G., Whinston, M.D., 1986. Free entry and social inefficiency. RAND Journal of Economics $17,48-58$.

Novick, B., Medero, J., Rosenblum, A., Barry, R., 2016. Breaking down the data: A closer look at bond fund AUM. Blackrock white paper.

Office of Management and Budget, 2014. Budget of the U.S. Government. Analytical Perspectives. Fiscal Year 2015. Technical Report. United States Government.

Oi, W.Y., 1971. A Disneyland dilemma: Two-part tariffs for a Mickey Mouse monopoly. Quarterly Journal of Economics 85, 77-96.

Osborne, G., 2015. Strengthening the incentive to save: a consultation on pensions tax relief. Her Majesty's Treasury Cm 9102.

Pástor, L., Stambaugh, R.F., 2012. On the size of the active management industry. Journal of Political Economy .

Pástor, L., Stambaugh, R.F., Taylor, L.A., 2015. Scale and skill in active management. Journal of Financial Economics 116, 23-45.

Pedersen, L.H., 2018. Sharpening the arithmetic of active management. Financial Analysts Journal $74,21-36$.

Perold, A.F., Salomon, R.S.J., 1991. The right amount of assets under management. Financial Analysts Journal 47, 31-39.

Petajisto, A., 2009. Why do demand curves for stocks slope down? Journal of Financial and Quantitative Analysis 44, 1013-1044.

Philippon, T., 2015. Has the U.S. finance industry become less efficient? on the theory and measurement of financial intermediation. American Economic Review 105, 1408-1438.

Philippon, T., Reshef, A., 2012. Wages and human capital in the U.S. financial industry: 1909-2006. Quarterly Journal of Economics 127, 1551-1609.

Phillips, D., 2013. Mutual fund urban myths. Morningstar Adviser, 80Retrieved at http://news .morningstar.com/articlenet/article. aspx?id=600657 on 11/15/2017.

Pine, A., 1989. GOP senators offer capital gains cut, new type of IRA. Los Angeles Times . Retrieved online on 10/19/2016.

Pool, V.K., Sialm, C., Stefanescu, I., 2016. It pays to set the menu: Mutual fund investment options in 401(k) plans. Journal of Finance 71, 1779-1812.

Romaniuk, K., 2013. Pension fund taxation and risk-taking: should we switch from the EET to the 
TEE regime? Annals of Finance 9, 573-588. doi:10.1007/s10436-012-0204-3.

Rosshirt, D.E., Parker, S.A., Pitts, D.A., 2014. Inside the Structure of Defined Contribution/401(k) Plan Fees, 2013: A study assessing the mechanics of the 'all-in' fee. Technical Report. Deloitte Consulting LLP.

Roussanov, N., Ruan, H., Wei, Y., 2018. Marketing mutual funds. Available at SSRN:https: //ssrn. com/abstract $=3093438$.

Rowley, Jr., J.J., Dickson, J.M., 2012. Mutual funds—-like ETFs— have trading volume. Technical Report. Vanguard.

Salop, S.C., 1979. Monopolistic competition with outside goods. Bell Journal of Economics 10, 141-156.

Shive, S., Yun, H., 2013. Are mutual funds sitting ducks? Journal of Financial Economics 107, 220-237.

Tergesen, A., Rubin, R., 2017. Talk of retirement savings cap rattles financial industry. Wall Street Journal 10/21/2017.

Thrift Savings Plan, 2018. Highlights.

Tirole, J., 1988. The Theory of Industrial Organization. MIT Press.

Tucker, M., 2011. Q\&a on bond funds and churn: Why turnover can be misleading. BlackRock Blog Retrieved at https://www.blackrockblog.com/2011/09/13/qa-on-bond-funds-a nd-churn-why-turnover-can-be-misleading/ on 11/15/2017.

Yan, X.S., 2008. Liquidity, investment style, and the relation between fund size and fund performance. Journal of Financial and Quantitative Analysis 43, 741-768. 